\title{
Análise de propostas didáticas de física orientadas por abordagens históricas ${ }^{+}$
}

Eider de Souza Silva ${ }^{1}$

Centro de Formação de Professores

Universidade Federal do Recôncavo da Bahia

Amargosa - BA

Elder Sales Teixeiral

Departamento de Física - Universidade Estadual de Feira de Santana

Feira de Santana - BA

Maria Cristina Martins Penido ${ }^{1}$

Instituto de Física - Universidade Federal da Bahia

Salvador - BA

\section{Resumo}

Este trabalho apresenta uma análise sobre as estratégias de transposição didática adotadas por autores de teses e dissertações brasileiras ao elaborarem propostas didáticas de física, orientadas por abordagens históricas. O trabalho é dividido em uma análise geral do conjunto de todas as propostas didáticas selecionadas e em uma análise pormenorizada das propostas didáticas que discutem concepções sobre Natureza da Ciência e que utilizam a Gravitação Universal de Newton como temática. As propostas didáticas foram selecionadas a partir da leitura dos títulos, dos resumos e, quando necessário, do sumário e da apresentação, a fim de selecionarmos os trabalhos que realmente interessavam a pesquisa. O processo de análise ocorreu a partir da leitura minuciosa das propostas e os critérios de análise foram definidos a partir do referencial teórico adotado (FORATO, 2009). Os resultados evidenciam que os autores dos trabalhos analisados adotaram a estratégia de interpretar os aspectos históricos enfatizados nos trechos das fontes primárias que compõem as propostas, a fim de contribuir para uma compreensão dia-

\footnotetext{
${ }^{+}$Analysis of didactic proposals of physics oriented by historical approaches

* Recebido: outubro de 2017. Aceito: julho de 2018.

${ }^{1}$ E-mails: eideruefs@yahoo.com.br; eldersate@gmail.com; mcrispenido@gmail.com
} 
crônica dos mesmos. Ademais, os episódios da história da Gravitação Universal, selecionados pelos autores dos trabalhos, contribuem para que as concepções sobre Natureza da Ciência adotadas nas propostas didáticas sejam abordadas ao longo da aplicação da proposta.

Palavras-chave: Abordagem histórica; Transposição Didática; Ensino de Física.

\begin{abstract}
This research shows an analysis of the strategies of didactic transposition adopted by authors of Brazilian theses and dissertations in the elaboration of didactic proposals of physics, guided by historical approaches. The research is divided into a general analysis of the set of all the didactic proposals selected and a detailed analysis of the didactic proposals that discuss conceptions about Nature of Science and that use Newton's Universal Gravitation as thematic. The didactic proposals were selected based on the reading of the titles, the abstracts and, when necessary, the summary and the presentation, in order to select the works that really interested the research. The analysis process was started from a thorough reading of the proposals and the analysis criteria were defined from the theoretical reference adopted (FORATO, 2009). The results show that the authors of the works analyzed adopted the strategy of interpreting the historical aspects emphasized in the excerpts from the primary sources that compose the proposals, in order to contribute to a diachronic understanding of the same. Furthermore, the episodes of the history of Universal Gravity, of the authors of the works, contributed to the conceptions about Nature of Nature to continue being didactic and approached throughout the application of the proposal.
\end{abstract}

Keywords: Historical approach; Didactic Transposition; Physics Teaching.

\title{
I. Introdução
}

A História da Ciência (HC) enquanto elemento capaz de melhorar a compreensão das concepções e métodos científicos, e humanizar a ciência, tornando-a mais interessante para os estudantes (MATTHEWS, 1995; PEDUZZI, 2001; BOSS, 2014), tem sido alvo de estudos por especialistas na área de ensino de ciências em todo o mundo, que há anos defendem a 
importância deste tipo de abordagem para todos os níveis da educação. Nesse contexto, a utilização da abordagem histórica no ensino de ciências, em especial no Ensino de Física (EF), pode contribuir para problematizar uma visão autoritária e preconceituosa da ciência, alimentando o anseio do estudante diante de uma prática tradicional nas salas de aula que busca apenas o produto final da Ciência, no intuito de simplesmente memoriza-la.

Em meio às premissas que envolvem a utilização da abordagem histórica no ensino de Ciências, o número de trabalhos empíricos que utilizam a $\mathrm{HC}$ no EF tem crescido nos últimos anos. Entretanto, ainda é grande a lacuna entre os argumentos favoráveis à utilização didática da HC no EF e a sua utilização empírica em aulas de física (SCHIRMER, 2011; TEIXEIRA, 2012a; TEIXEIRA, 2012b).

A despeito dos argumentos aderentes à utilização da abordagem histórica no EF, Teixeira et al. (2012a; 2012b) apontam a necessidade do desenvolvimento de trabalhos voltados para sala de aula, capazes de evidenciar os reais benefícios da utilização desse tipo de abordagem em ambiente escolar. Diante disso, o objetivo do referido artigo é analisar as estratégias de transposição didática adotadas por autores de teses e dissertações brasileiras, ao elaborarem propostas didáticas de física orientadas por abordagens históricas. O trabalho é dividido em uma análise geral do conjunto de todas as propostas didáticas selecionadas e em uma análise pormenorizada das propostas didáticas que discutem concepções sobre Natureza da Ciência (NdC) e que utilizam a Gravitação Universal de Newton como temática

Esperamos, com a análise do processo de transposição didática que envolve a utilização da abordagem histórica, contribuir para o debate que envolve a assimetria entre o grande número de argumentos favoráveis à utilização da abordagem histórica no EF e a escassez de intervenções didáticas em sala de aula sobre essa temática, evidenciada por Teixeira et al. (2012a; 2012b). Assim, contribuir para aproximar de forma efetiva e com exemplos empíricos a $\mathrm{HC}$ do EF.

\section{Metodologia}

A fim de atender aos objetivos estabelecidos nesse trabalho, foi adotado o seguinte percurso metodológico:

- Levantamento das dissertações e teses para análise;

- Definição dos critérios de corte;

- Definição dos critérios de análise pormenorizada;

- Análise geral das propostas didáticas selecionadas;

- Análise pormenorizada das propostas didáticas que atendem aos critérios de corte.

O recorte adotado para a busca de propostas didáticas levou em consideração os trabalhos digitalizados e disponíveis na internet até 2017. Utilizamos trabalhos disponíveis nos bancos de teses e dissertações dos programas de pós-graduação especializados em ensino de 
ciências, de centros universitários, e de sistemas públicos de busca ${ }^{2}$. O método de busca das propostas didáticas representa uma limitação do trabalho em questão. Tendo em vista, que não existe garantia que todas as dissertações e teses defendidas, que apresentam propostas didáticas de física orientadas por abordagens históricas, objeto de interesse deste trabalho, estejam disponibilizadas nos bancos de buscas utilizados. Por consequência, devem existir propostas didáticas envolvendo a $\mathrm{HC}$ e o EF defendidas em décadas anteriores, ou mesmo nas três últimas décadas, que não foram disponibilizadas na rede e, consequentemente, não foram selecionadas por conta do método de coleta de dados utilizados para essa pesquisa.

A busca das propostas didáticas de física, orientadas pela $\mathrm{HC}$, se deu durante todo o processo que envolveu a revisão de literatura. A seleção destes trabalhos se deu através da utilização de palavras-chaves, como por exemplo: ensino de ciências, Ensino de Física, abordagem contextual, abordagem histórico-filosófica, História da Ciência, proposta didática e sequência didática. Diante dos trabalhos selecionados, foi realizada a leitura dos títulos, dos resumos, e quando necessário do sumário e da apresentação, a fim de selecionarmos os trabalhos que realmente interessavam a pesquisa. Inicialmente, foram selecionados 43 trabalhos 3 que apresentavam propostas didáticas de física, orientadas por abordagens históricas, para em seguida ser realizado o processo de análise geral e pormenorizada.

Com o número de propostas selecionadas, foi realizada, inicialmente, uma análise geral de todos os trabalhos. A análise geral visa contribuir para a identificação de dados relevantes para a compreensão do processo de transposição didática dos trabalhos e, consequentemente, para a análise pormenorizada das propostas didáticas que atendem aos critérios de corte. Além disso, visa fornecer informações relevantes para a elaboração de um panorama sobre as propostas didáticas de física orientadas por abordagens históricas no Brasil, desenvolvidas nos programas de pós-graduação em ensino de ciências.

Antes da definição dos critérios de análise, foram adotados dois critérios de corte para o processo de análise pormenorizada que foi realizada nesta pesquisa. O primeiro ponto é analisar apenas propostas que almejam discutir concepções sobre $\mathrm{NdC}$ em seus objetivos pedagógicos. Tal escolha parte da importância atribuída à abordagem histórica como uma estratégia pedagógica capaz de contribuir, significativamente, para a compreensão sobre $\mathrm{NdC}$.

O segundo critério de corte visa analisar apenas as propostas didáticas que utilizam a GU como temática, em função deste tema evidenciar debates conceituais importantes para modificar a visão de mundo da humanidade entre os séculos XVI e XVII e assim contribuir para o questionamento a respeito de visões sobre $\mathrm{NdC}$.

\footnotetext{
2 Biblioteca Digital Brasileira de Teses e Dissertações (BDTD); Portal Domínio Público; Biblioteca Digital da UNICAMP; Banco de Teses e Dissertações CAPES; Banco de produção acadêmica do Mestrado Nacional Profissional em Ensino de Física (MNPEF); Pós Graduação em Educação Científica e Tecnológica, por exemplo.

3 Além dos trabalhos selecionados, tivemos acesso a outras duas propostas didáticas, uma dissertação (TEIXEIRA, 2003) e uma tese (TEIXEIRA, 2010), sobre a abordagem contextual e o Ensino de Física, que não foram consideradas para evitar enviesamento na análise por se tratarem de trabalhos elaborados por um dos autores deste trabalho.
} 
Os critérios estão definidos da seguinte forma:

Quadro 1: Critérios de análise e seus objetivos.

\section{Aspectos epistemológicos a enfatizar}

2. Seleção dos episódios históricos

3. Nível de aprofundamento dos aspectos históricos

4. Fontes dos textos utilizados.
Analisar quais e como as visões sobre $\mathrm{NdC}$ são abordadas nas propostas didáticas de física, orientadas por uma abordagem histórica.

Analisar se os episódios históricos selecionados contribuem para discutir as visões sobre a $\mathrm{NdC}$ abordada.

Analisar se os episódios históricos selecionados estão num grau de aprofundamento/detalhamento adequado para o nível de escolaridade.

Analisar quais e como são utilizadas as fontes históricas nos textos didáticos que compõem as propostas didáticas.

Analisar os desafios descritos pelos autores para a aplicação das propostas de física orientadas por uma abordagem histórica em sala de aula.

Fonte: Elaborada pelos autores da pesquisa.

Os critérios para analisar como os autores de teses e dissertações brasileiras lidam com o processo de transposição didática ao elaborarem propostas didáticas de física, orientadas por abordagens históricas, emergiram do referencial teórico adotado (FORATO, 2009) ${ }^{4}$. Sendo estes relevantes para uma compreensão sobre o processo de transposição didática que envolve utilizar a abordagem histórica dentro da sala de aula, capaz de contribuir para a efetivação de resultados empíricos sobre a $\mathrm{HC}$ no Ensino de Ciências, em especial no EF.

De acordo com Chevallard (1991), a transposição didática é caracterizada como uma estratégia importante para tornar o conhecimento científico, produzido pelos cientistas, num conhecimento acessível que forma os manuais de ensino, assim como as propostas didáticas analisadas. Em vista disso, a programação do processo de ensino e aprendizagem, em forma de propostas didáticas, que possibilitam a aquisição de seus conhecimentos, é uma característica a ser considerada para tornar o saber a ensinar potencialmente ensinável (CHEVALLARD, 1991). Por sua vez, esse processo deve respeitar os pressupostos historiográficos para o uso didático da abordagem histórica no EF (FORATO, 2009).

\footnotetext{
4 O estudo realizado por Forato (2009) é amparado pelo conceito de Transposição Didática de Chevallard (1991). Todavia, ao reconhecer que esse processo requer estratégias específicas para o uso didático da HC no EF, a autora define obstáculos que devem ser superados ou contornados para a utilização deste tipo de abordagem em contexto real de sala de aula. Tais obstáculos representam os parâmetros que subsidiaram a definição dos critérios adotados neste trabalho para a análise das propostas didáticas de física, orientadas por abordagens históricas, que atendem aos critérios de corte.
} 


\section{Resultados e Análise}

\section{III.1 Análise Geral das propostas didáticas de física, orientadas por abordagens históri- cas}

Inicialmente, apresentamos uma lista com as 43 propostas selecionadas, publicadas nas formas de dissertação/tese (Quadro 2). Essas propostas foram nomeadas nas tabelas por ordem numérica, cujas referências completas encontram-se em anexo (Anexo A).

Quadro 2: Propostas didáticas selecionadas.

\begin{tabular}{|c|c|c|c|c|}
\hline 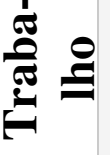 & 象 & $\begin{array}{l}\text { Dissertação } \\
\text { (D)/Tese } \\
\text { (T) }\end{array}$ & Autor & Titulo \\
\hline 1 & 1996 & D & $\begin{array}{l}\text { VANNUCCHI, } \\
\text { A. I. }\end{array}$ & $\begin{array}{l}\text { História e Filosofia da Ciência: da teoria para a sala de } \\
\text { aula. }\end{array}$ \\
\hline 2 & 1998 & $\mathbf{T}$ & $\begin{array}{l}\text { PEDUZZI, L. O. } \\
\text { Q. }\end{array}$ & $\begin{array}{l}\text { As concepções espontâneas, a resolução de problemas e a } \\
\text { história e a filosofia da ciência em um curso de mecânica. }\end{array}$ \\
\hline 3 & 2000 & D & $\begin{array}{l}\text { TEODORO, S. } \\
\text { R. }\end{array}$ & $\begin{array}{l}\text { A história da ciência e as concepções alternativas de } \\
\text { estudantes como subsídios para o planejamento de um } \\
\text { curso sobre atração gravitacional. }\end{array}$ \\
\hline 4 & 2004 & D & BASSO, A. C. & $\begin{array}{c}\text { O átomo de Bohr no nível médio: uma análise sob o } \\
\text { referencial lakatosiano. }\end{array}$ \\
\hline 5 & 2005 & $\mathbf{T}$ & GATTI, S. R. T. & $\begin{array}{l}\text { Uma análise de uma ação didática centrada na utilização } \\
\text { da história da ciência: uma contribuição para a formação } \\
\text { inicial do docente de física. }\end{array}$ \\
\hline 6 & 2005 & D & MELO, A. C. S. & $\begin{array}{l}\text { Contribuições da epistemologia histórica de Bachelard no } \\
\text { estudo da evolução dos conceitos da óptica. }\end{array}$ \\
\hline 7 & 2006 & D & $\begin{array}{l}\text { PORTELA, S. I. } \\
\text { C. }\end{array}$ & $\begin{array}{l}\text { O uso de casos históricos no ensino de física: um exem- } \\
\text { plo em torno da temática do horror da natureza ao vácuo. }\end{array}$ \\
\hline 8 & 2006 & D & $\begin{array}{l}\text { DUARTE, R. C. } \\
\text { B. }\end{array}$ & $\begin{array}{l}\text { Módulo de ensino de mecânica newtoniana com uso de } \\
\text { abordagem CTS - histórica. }\end{array}$ \\
\hline 9 & 2008 & $\mathbf{T}$ & SILVA, O. H. M. & $\begin{array}{l}\text { Um estudo sobre a estruturação e aplicação de uma estra- } \\
\text { tégia de ensino de física inspirada em lakatos com a re- } \\
\text { construção racional didática para auxiliar a preparar os } \\
\text { estudantes para debates racionais entre teorias e /ou con- } \\
\text { cepções rivais. }\end{array}$ \\
\hline 10 & 2008 & D & SOUZA, J. A. & $\begin{array}{l}\text { Uma abordagem histórica para o ensino do princípio da } \\
\text { inércia. }\end{array}$ \\
\hline 11 & 2009 & $\mathbf{T}$ & $\begin{array}{l}\text { FORATO, T. C. } \\
\text { M. }\end{array}$ & $\begin{array}{l}\text { A Natureza da Ciência como saber escolar: um estudo de } \\
\text { caso a partir da história da luz. }\end{array}$ \\
\hline 12 & 2009 & D & IACHEL, G. & $\begin{array}{l}\text { Um estudo exploratório sobre o ensino de astronomia na } \\
\text { formação continuada de professores. }\end{array}$ \\
\hline 13 & 2009 & D & SILVA, W. L. & $\begin{array}{l}\text { A importância de uma abordagem epistemológica na } \\
\text { graduação em física. }\end{array}$ \\
\hline 14 & 2009 & D & SILVA, D. A. & $\begin{array}{l}\text { Aspectos epistemológicos da Física newtoniana na } \\
\text { formação científica. }\end{array}$ \\
\hline 15 & 2009 & D & DUQUE, E. R. & $\begin{array}{l}\text { História da ciência e o uso da instrumentalização: cons- } \\
\text { trução de aparato histórico-científico simples como estra- } \\
\text { tégia de ensino }\end{array}$ \\
\hline 16 & 2010 & D & SILVA, B. V. C. & $\begin{array}{c}\text { Controvérsias sobre a natureza da luz: uma aplicação } \\
\text { didática }\end{array}$ \\
\hline
\end{tabular}




\begin{tabular}{|c|c|c|c|c|}
\hline$\frac{\sigma}{\sigma}$ & 를 & $\begin{array}{l}\text { Dissertação } \\
\text { (D)/Tese } \\
\text { (T) }\end{array}$ & Autor & Titulo \\
\hline 17 & 2010 & $\mathbf{D}$ & PEREIRA, R. A. & $\begin{array}{l}\text { A física da música no renascimento: uma abordagem } \\
\text { histórico-epistemológica. }\end{array}$ \\
\hline 18 & 2010 & $\mathbf{D}$ & $\begin{array}{l}\text { ARTHURY, L. } \\
\text { H. M. }\end{array}$ & $\begin{array}{l}\text { A cosmologia moderna a luz dos elementos da epistemo- } \\
\text { logia de Lakatos. }\end{array}$ \\
\hline 19 & 2010 & $\mathbf{T}$ & MELO, A. C. S. & $\begin{array}{l}\text { Transposição didática do modelo de Huygens: uma pro- } \\
\text { posta para a física escolar. }\end{array}$ \\
\hline 20 & 2011 & D & MORAIS, A. V. & $\begin{array}{c}\text { O conceito de energia através da história: a história e a } \\
\text { filosofia da ciência como caminho para inserir física } \\
\text { moderna e contemporânea na primeira série do ensino } \\
\text { médio }\end{array}$ \\
\hline 21 & 2011 & $\mathbf{T}$ & DANIEL, G. P. & $\begin{array}{l}\text { História da ciência em um curso de licenciatura em físi- } \\
\text { ca: a gravitação newtoniana e a gravitação einsteiniana } \\
\text { como exemplo. }\end{array}$ \\
\hline 22 & 2011 & $\mathbf{D}$ & $\begin{array}{l}\text { HENRIQUE, A. } \\
\text { B }\end{array}$ & $\begin{array}{c}\text { Discutindo a Natureza da Ciência a partir de episódios da } \\
\text { história da Cosmologia. }\end{array}$ \\
\hline 23 & 2011 & D & $\begin{array}{l}\text { CORDEIRO, M. } \\
\text { D. }\end{array}$ & $\begin{array}{l}\text { Dos Curie a Rutherford: aspectos históricos e epistemo- } \\
\text { lógicos da radioatividade na formação científica. }\end{array}$ \\
\hline 24 & 2011 & D & FILHO, M. A. & Demanda epistemológica no ensino de física. \\
\hline 25 & 2012 & D & $\begin{array}{l}\text { SCHIRMER, S. } \\
\text { B. }\end{array}$ & $\begin{array}{l}\text { Textos originais de cientistas e textos sobre história das } \\
\text { ideias da ciência na formação inicial de professores de } \\
\text { Física. }\end{array}$ \\
\hline 26 & 2012 & $\mathbf{T}$ & MOURA, B. A. & $\begin{array}{l}\text { Formação crítica-transformadora de professores de Físi- } \\
\text { ca: uma proposta a partir da história da ciência. }\end{array}$ \\
\hline 27 & 2012 & $\mathbf{D}$ & JARDIM, W. T. & $\begin{array}{l}\text { A abordagem histórico-filosófica como caminho para se } \\
\text { introduzir o estudo de cosmologia no ensino }\end{array}$ \\
\hline 28 & 2012 & D & $\begin{array}{l}\text { FERNANDES, } \\
\text { H. S. }\end{array}$ & $\begin{array}{l}\text { Narrativas históricas: discutindo a Natureza da Ciência } \\
\text { através de uma abordagem histórico-filosófica }\end{array}$ \\
\hline 29 & 2013 & D & ARAÚJO, B. C. & $\begin{array}{l}\text { História da ciência como estratégia didática no ensino } \\
\text { médio: um breve olhar de conteúdos da óptica }\end{array}$ \\
\hline 30 & 2013 & D & $\begin{array}{l}\text { OLIVEIRA, W. } \\
\text { C. }\end{array}$ & $\begin{array}{l}\text { Ensinado sobre a Natureza da Ciência: uma abordagem } \\
\text { explícita e contextualizada a partir da história do vácuo }\end{array}$ \\
\hline 31 & 2013 & $\mathbf{T}$ & $\begin{array}{l}\text { RESQUETTI, S. } \\
\text { O. }\end{array}$ & $\begin{array}{l}\text { Uma sequência didática para o ensino da radioatividade } \\
\text { no nível médio, com enfoque na história e filosofia da } \\
\text { ciência e no movimento CTS }\end{array}$ \\
\hline 32 & 2014 & D & SOUZA, R. S. & $\begin{array}{c}\text { Desafios da história da física na sala de aula: sequência } \\
\text { didática, caderno de campo e uma leitura das concepções } \\
\text { docente e discente }\end{array}$ \\
\hline 33 & 2014 & D & $\begin{array}{l}\text { MONTEIRO, M. } \\
\text { M. }\end{array}$ & $\begin{array}{l}\text { Inércia e Natureza da Ciência no ensino de física: uma } \\
\text { sequência didática centrada no desenvolvimento histórico } \\
\text { do conceito de inércia }\end{array}$ \\
\hline 34 & 2014 & D & VIEIRA, P. C. & $\begin{array}{c}\text { Perspectivas sobre a evolução histórica do conceito de } \\
\text { luz e sua integração com a fotografia para o ensino de } \\
\text { óptica }\end{array}$ \\
\hline 35 & 2014 & D & MELLO, A. D. & $\begin{array}{l}\text { A história e a filosofia da ciência como um caminho para } \\
\text { problematizar o tema energia nuclear no ensino médio: as } \\
\text { imagens como uma estratégia didática }\end{array}$ \\
\hline 36 & 2015 & D & REIS, U. V. & $\begin{array}{l}\text { Os conceitos de espaço e tempo no ensino de física: uma } \\
\text { possibilidade de atuação em sala de aula }\end{array}$ \\
\hline 37 & 2015 & D & NETTO, M. F. S. & $\begin{array}{l}\text { O efeito fotoelétrico e a natureza da luz através de um } \\
\text { enfoque histórico-filosófico: uma proposta }\end{array}$ \\
\hline 38 & 2016 & D & SIMON, R. A. & $\begin{array}{l}\text { Do geocentrismo à gravitação universal: proposta e im- } \\
\text { plementação de uma sequência didática para o ensino }\end{array}$ \\
\hline
\end{tabular}




\begin{tabular}{|c|c|c|c|c|}
\hline 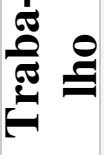 & $\gtreqless$ & $\begin{array}{l}\text { Dissertação } \\
\text { (D)/Tese } \\
\text { (T) }\end{array}$ & Autor & Titulo \\
\hline & & & & médio \\
\hline 39 & 2016 & D & MATOS, J. A. & $\begin{array}{l}\text { Apresentando conceitos do movimento de queda dos } \\
\text { corpos no ensino fundamental através de um aporte histó- } \\
\text { rico e epistemológico }\end{array}$ \\
\hline 40 & 2016 & D & FUCHS, E. I. & $\begin{array}{l}\text { Teoria da relatividade restrita: uma introdução histórico- } \\
\text { epistemológica e conceitual voltada ao ensino médio }\end{array}$ \\
\hline 41 & 2016 & D & $\begin{array}{l}\text { NASCIMENTO, } \\
\text { B. A. }\end{array}$ & $\begin{array}{l}\text { Sequência didática para ensino e aprendizagem do con- } \\
\text { ceito de força numa abordagem histórica }\end{array}$ \\
\hline 42 & 2017 & D & SANTOS, J. M. & $\begin{array}{l}\text { O ensino da gravitação universal de newton através da } \\
\text { história da ciência e da argumentação: desenvolvimento e } \\
\text { análise de uma sequência didática }\end{array}$ \\
\hline 43 & 2017 & D & FONSECA, D. S. & $\begin{array}{l}\text { Ensinando ciência e sobre ciência com a utilização de } \\
\text { fontes primárias da história do vácuo e da pressão atmos- } \\
\text { férica }\end{array}$ \\
\hline
\end{tabular}

Fonte: Elaborada pelo autor desta pesquisa baseado no trabalho de Teixeira (2012a; 2012b).

A partir dos dados descritos no quadro 2, foi elaborado o gráfico 1.

Gráfico 1: Distribuição por década, da quantidade de propostas didáticas selecionadas (total = 43 propostas).

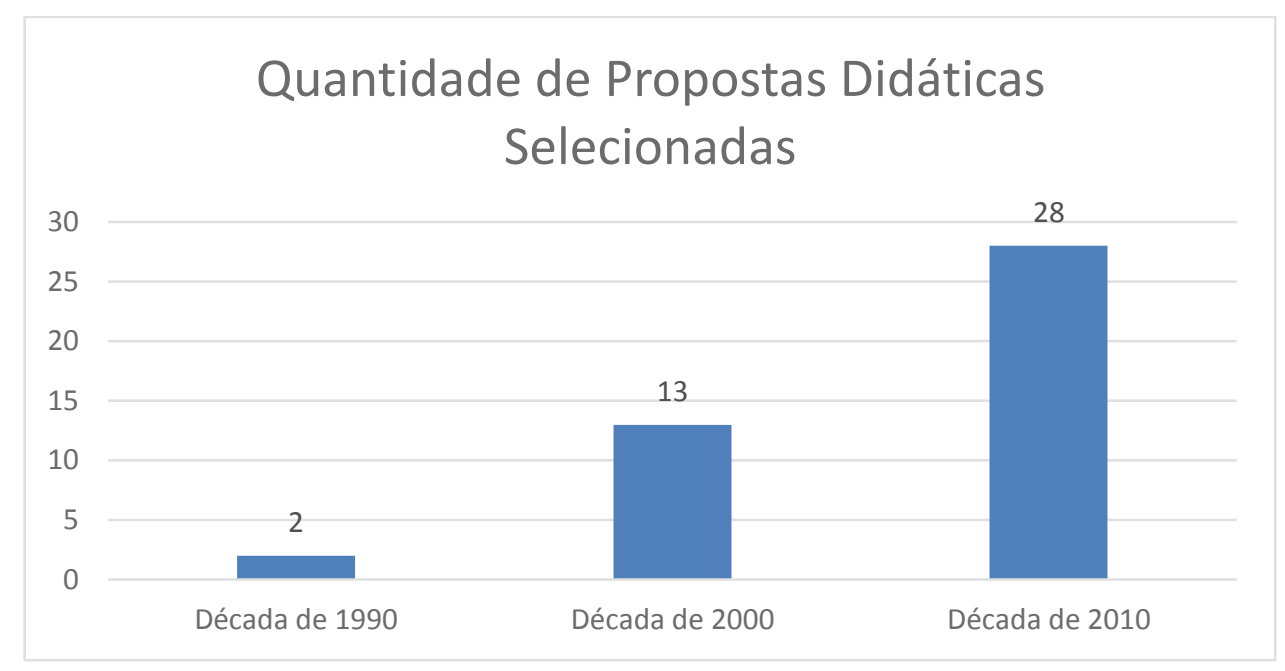

Fonte: Elaborada pelos autores da pesquisa.

Os dados do gráfico1 evidenciam um crescimento do número de propostas produzidas nas três décadas que buscam integrar a HC ao EF. Na década atual, em oito anos de busca (2010 a 2017), o número de trabalhos selecionados (28 propostas didáticas) é mais que o dobro que o número de propostas selecionadas na década anterior (13 propostas didáticas), o que reflete uma tendência de crescimento na área. Esses resultados também encontram acordo nos trabalhos desenvolvidos por Teixeira et al. (2012a; 2012b), que analisaram artigos de revistas, 
assim como no trabalho de Carvalho e Vannucchi (1996) que analisaram as atas dos congressos especializados no EF, realizados no início da década de noventa.

Para que venhamos compreender o processo de transposição didática adotado pelos autores das propostas didáticas de física, orientadas por abordagens históricas, será realizada, a seguir, a análise geral de todos os trabalhos selecionadas. Serão levados em consideração os seguintes aspectos: temática/conteúdo histórico abordado; objetivos pedagógicos; fontes dos textos utilizados; nível de ensino/duração de aplicação; e estratégias de ensino.

Quadro 3: Caracterização geral das propostas didáticas.

\begin{tabular}{|c|c|c|c|c|c|}
\hline 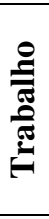 & $\begin{array}{c}\text { Temática } \\
\text { - } \\
\text { Conteúdo Histó- } \\
\text { rico } \\
\end{array}$ & $\begin{array}{l}\text { Objetivos Peda- } \\
\text { gógicos }\end{array}$ & $\begin{array}{l}\text { Fontes dos } \\
\text { Textos }\end{array}$ & $\begin{array}{c}\text { Nível de } \\
\text { Ensino } \\
\text { - } \\
\text { Duração de } \\
\text { Aplicação } 5 \\
\end{array}$ & Estratégias de Ensino \\
\hline 1 & $\begin{array}{c}\text { Ótica } \\
- \\
\text { Aperfeiçoamento } \\
\text { da Luneta. }\end{array}$ & $\begin{array}{c}\text { Discussões que } \\
\text { envolvem a rela- } \\
\text { ção entre Ciência e } \\
\text { Tecnologia e o } \\
\text { papel dos referen- } \\
\text { tes teóricos dos } \\
\text { cientistas na ob- } \\
\text { servação e inter- } \\
\text { pretação dos dados }\end{array}$ & $\begin{array}{l}\text { Textos elabo- } \\
\text { rados pela } \\
\text { própria autora. }\end{array}$ & $\begin{array}{l}\text { Ensino Mé- } \\
\text { dio } \\
- \\
\text { Não especifi- } \\
\text { cou. }\end{array}$ & $\begin{array}{l}\text { Aula expositiva que possi- } \\
\text { bilitou discussão, ativida- } \\
\text { des em grupo, resoluções } \\
\text { de problemas. }\end{array}$ \\
\hline 2 & Mecânica $^{6}$ & $\begin{array}{l}\text { Promover a evolu- } \\
\text { ção conceitual, a } \\
\text { resolução signifi- } \\
\text { cativa de proble- } \\
\text { mas de lápis e } \\
\text { papel e uma con- } \\
\text { cepção não empi- } \\
\text { rista do desenvol- } \\
\text { vimento científico }\end{array}$ & $\begin{array}{l}\text { Textos elabo- } \\
\text { rados pelo } \\
\text { autor. }\end{array}$ & $\begin{array}{c}\text { Formação de } \\
\text { professores } \\
- \\
\text { Um semestre. }\end{array}$ & $\begin{array}{l}\text { Leitura e discussão de } \\
\text { textos, aula expositiva, } \\
\text { resoluções de problemas, } \\
\text { resolução de questionário } \\
\text { e formulação de questões. }\end{array}$ \\
\hline 3 & $\begin{array}{c}\text { Mecânica } \\
- \\
\text { Atração Gravita- } \\
\text { cional }\end{array}$ & $\begin{array}{l}\text { Questionar o pro- } \\
\text { cesso de constru- } \\
\text { ção da Ciência e a } \\
\text { prática de ensino }\end{array}$ & $\begin{array}{l}\text { Textos elabo- } \\
\text { rados pelo } \\
\text { próprio autor. }\end{array}$ & $\begin{array}{l}\text { Formação de } \\
\text { professores }\end{array}$ & $\begin{array}{l}\text { Trabalho coletivo com } \\
\text { realização de debates e } \\
\text { sínteses. }\end{array}$ \\
\hline 4 & $\begin{array}{c}\text { Física Moderna } \\
\text { - } \\
\text { Átomo de Bohr }\end{array}$ & $\begin{array}{c}\text { Contribuir para o } \\
\text { ensino do átomo } \\
\text { de Bohr no nível } \\
\text { médio }\end{array}$ & $\begin{array}{l}\text { Texto elabora- } \\
\text { do pelo autor }\end{array}$ & $\begin{array}{l}\text { Formação de } \\
\text { professores } \\
- \\
\text { Não especifi- } \\
\text { cou }\end{array}$ & Leitura de texto \\
\hline
\end{tabular}

\footnotetext{
${ }^{5}$ Característica que aponta o tempo e o nível de aplicação proposta, porém não procura afirmar se a mesma foi realmente aplicada em sala de aula.

${ }^{6} \mathrm{O}$ texto da proposta é composto de quatro livros: Livro 1: Introdução ao estudo de vetores, à cinemática unidimensional e a resolução de problemas de física; Livro 2: Força e Movimento: de Thales a Galileu; Livro 3: Força e Movimento: de Descartes a Newton; Livro 4: A teoria da relatividade especial: contexto histórico e conceitos básicos.

7 O trabalho em questão não foca na elaboração de uma proposta didática, apenas na construção de um texto, baseado no referencial de Lakatos, com o intuito de contribuir para o ensino do átomo de Bohr no nível médio.
} 


\begin{tabular}{|c|c|c|c|c|c|}
\hline 竝 & $\begin{array}{c}\text { Temática } \\
\text { - } \\
\text { Conteúdo Histó- } \\
\text { rico }\end{array}$ & $\begin{array}{l}\text { Objetivos Peda- } \\
\text { gógicos }\end{array}$ & $\begin{array}{l}\text { Fontes dos } \\
\text { Textos }\end{array}$ & $\begin{array}{c}\text { Nível de } \\
\text { Ensino } \\
\text { - } \\
\text { Duração de } \\
\text { Aplicação } 5\end{array}$ & Estratégias de Ensino \\
\hline 5 & $\begin{array}{c}\text { Mecânica } \\
- \\
\text { Atração Gravita- } \\
\text { cional }\end{array}$ & $\begin{array}{l}\text { Concepções alter- } \\
\text { nativas/ Questio- } \\
\text { nar uma visão } \\
\text { simplista e cumu- } \\
\text { lativa da Ciência }\end{array}$ & $\begin{array}{l}\text { Textos elabo- } \\
\text { rados pelo } \\
\text { próprio autor }\end{array}$ & $\begin{array}{c}\text { Formação de } \\
\text { professores } \\
- \\
12 \text { meses }\end{array}$ & $\begin{array}{l}\text { Aulas expositivas, debates } \\
\text { em grupo, construção do } \\
\text { modelo de mundo a partir } \\
\text { das concepções prévia dos } \\
\text { alunos e reflexão sobre a } \\
\text { prática docente }\end{array}$ \\
\hline 6 & Ótica 8 & $\begin{array}{l}\text { Contribuir para } \\
\text { uma visão mais } \\
\text { crítica da natureza } \\
\text { e construção da } \\
\text { ciência óptica na } \\
\text { formação inicial } \\
\text { de professores e } \\
\text { pesquisadores }\end{array}$ & $\begin{array}{l}\text { Texto elabora- } \\
\text { do pelo autor } 9\end{array}$ & $\begin{array}{c}\text { Formação de } \\
\text { professores } \\
- \\
16 \text { horas-aula }\end{array}$ & $\begin{array}{l}\text { Leitura prévia dos textos e } \\
\text { aulas expositivas dialoga- } \\
\text { das }\end{array}$ \\
\hline 7 & $\begin{array}{l}\text { Mecânica } \\
\quad- \\
\text { Hidrostática } \\
\text { (Natureza do } \\
\quad \text { vácuo) }\end{array}$ & $\begin{array}{l}\text { Romper com a } \\
\text { perspectiva de- } \\
\text { formada do ensino } \\
\text { de ciências basea- } \\
\text { do na mera trans- } \\
\text { missão dos produ- } \\
\text { tos do conheci- } \\
\text { mento científico }\end{array}$ & $\begin{array}{l}\text { Texto elabora- } \\
\text { do pelo pró- } \\
\text { prio autor }\end{array}$ & $\begin{array}{c}\text { Ensino Mé- } \\
\text { dio } 10 \\
- \\
\text { Não especifi- } \\
\text { cou }\end{array}$ & $\begin{array}{c}\text { Roda de leitura, debate, } \\
\text { resolução de questões } \\
\text { cotidianas, proposta e } \\
\text { construção de experimen- } \\
\text { tos }\end{array}$ \\
\hline 8 & $\begin{array}{c}\text { Mecânica } \\
- \\
\text { Satélites (CTS) }\end{array}$ & $\begin{array}{l}\text { Auxiliar professo- } \\
\text { res de física a } \\
\text { ensinar Mecânica } \\
\text { Clássica a partir } \\
\text { de um contexto } \\
\text { social e histórico } \\
\end{array}$ & $\begin{array}{l}\text { Texto elabora- } \\
\text { do pelo pró- } \\
\text { prio autor }{ }^{11}\end{array}$ & $\begin{array}{l}\text { Ensino Mé- } \\
\text { dio } \\
- \\
\text { Não especifi- } \\
\text { cou }\end{array}$ & $\begin{array}{l}\text { Leitura de textos e exposi- } \\
\text { ção dialogada }\end{array}$ \\
\hline 9 & $\begin{array}{c}\text { Termologia } \\
- \\
\text { Calor e Tempera- } \\
\text { tura }\end{array}$ & $\begin{array}{l}\text { Exemplificar situ- } \\
\text { ações racionais de } \\
\text { comparação entre } \\
\text { teorias rivais }\end{array}$ & $\begin{array}{l}\text { Textos elabo- } \\
\text { rados pelo } \\
\text { próprio autor }\end{array}$ & $\begin{array}{l}\text { Formação de } \\
\text { professores } \\
- \\
5 \text { horas-aula }\end{array}$ & $\begin{array}{c}\text { Aulas expositivas, leitura } \\
\text { de textos, experimento } \\
\text { demonstrativo e exibição } \\
\text { de filmes }\end{array}$ \\
\hline 10 & $\begin{array}{c}\text { Mecânica } \\
- \\
\text { Força e Movi- } \\
\text { mento (Princípio } \\
\text { da Inércia) }\end{array}$ & $\begin{array}{l}\text { Problematizar } \\
\text { concepções de } \\
\text { força e movimen- } \\
\text { to, discutir con- } \\
\text { cepções sobre } \\
\text { NdC }\end{array}$ & $\begin{array}{l}\text { Textos elabo- } \\
\text { rados pelo } \\
\text { próprio autor }\end{array}$ & $\begin{array}{c}\text { Ensino médio } \\
- \\
20 \text { horas- }^{-} \\
\text {aula }^{12}\end{array}$ & $\begin{array}{l}\text { Aula expositiva, leitura } \\
\text { prévia e coletiva de textos, } \\
\text { resolução de problemas, } \\
\text { debate coletivo, resumo } \\
\text { dos textos }\end{array}$ \\
\hline 11 & Ótica & Utilização da & Textos elabo- & Ensino médio & Aulas expositivas, leitura e \\
\hline
\end{tabular}

\footnotetext{
8 A proposta em questão discute aspectos da evolução da óptica sem realizar um recorte histórico específico sobre o assunto.

${ }^{9}$ A Epistemologia Histórica de Bachelard no Estudo da Evolução da Óptica: as controvérsias acerca da natureza da luz.

${ }^{10}$ De acordo com o próprio autor, "Essas lições poderão ser utilizadas também no início de um curso para o $1^{\circ} \mathrm{e}$ $2^{\circ}$ ano para mostrar como é a dinâmica de construção do conhecimento científico” (PORTELA, 2006, p. 94).

11 O material elaborado pelo autor é denominado de Módulo de Ensino, o mesmo é organizado em dois CDS com apresentações em Power Point e em dois textos de apoio, além de um material de apoio ao professor.
}

12 Para essa proposta didática em questão cada hora aula possui a duração de 35 (trinta e cinco) minutos. 


\begin{tabular}{|c|c|c|c|c|c|}
\hline 竞 & $\begin{array}{c}\text { Temática } \\
\text { - } \\
\text { Conteúdo Histó- } \\
\text { rico } \\
\end{array}$ & $\begin{array}{l}\text { Objetivos Peda- } \\
\text { gógicos }\end{array}$ & $\begin{array}{l}\text { Fontes dos } \\
\text { Textos }\end{array}$ & $\begin{array}{c}\text { Nível de } \\
\text { Ensino } \\
\text { - } \\
\text { Duração de } \\
\text { Aplicação } 5 \\
\end{array}$ & Estratégias de Ensino \\
\hline & & $\begin{array}{l}\text { história da ciência } \\
\text { em ambiente esco- } \\
\text { lar com a finalida- } \\
\text { de de discutir } \\
\text { aspectos sobre } \\
\text { NdC } \\
\end{array}$ & $\begin{array}{c}\text { rados pela } \\
\text { própria autora }\end{array}$ & 20 horas-aula & $\begin{array}{l}\text { discussão de textos, reso- } \\
\text { lução de questões, debate, } \\
\text { atividade teatral, quebra- } \\
\text { cabeça, avaliação e Festi- } \\
\text { val Cultural }\end{array}$ \\
\hline 12 & $\begin{array}{c}\text { Astronomia } \\
\quad- \\
\text { Sistema Solar }\end{array}$ & $\begin{array}{l}\text { Desenvolvimento } \\
\text { profissional quan- } \\
\text { to à prática de } \\
\text { ensino de conteú- } \\
\text { dos relacionados à } \\
\text { Astronomia. } \\
\end{array}$ & $\begin{array}{l}\text { Textos histori- } \\
\text { ográficos }\end{array}$ & $\begin{array}{c}\text { Formação de } \\
\text { professores } \\
- \\
33 \text { horas. }\end{array}$ & $\begin{array}{c}\text { Leituras e discussão dos } \\
\text { textos, atividade prática } \\
\text { (Oficina para a construção } \\
\text { de uma luneta) e observa- } \\
\text { ção celeste com o material } \\
\text { produzido } \\
\end{array}$ \\
\hline 13 & $\begin{array}{l}\text { Epistemologia da } \\
\text { ciência }^{13}\end{array}$ & $\begin{array}{l}\text { Incentivar o estu- } \\
\text { do sobre a Filoso- } \\
\text { fia da Ciência }\end{array}$ & $\begin{array}{l}\text { Texto elabora- } \\
\text { do pelo pró- } \\
\text { prio autor }^{14}\end{array}$ & $\begin{array}{c}\text { Formação de } \\
\text { professores } \\
- \\
8 \text { horas aula }\end{array}$ & $\begin{array}{l}\text { Aulas expositivas, apre- } \\
\text { sentação de textos, deba- } \\
\text { tes, resolução de situações } \\
\text { problemas }\end{array}$ \\
\hline 14 & $\begin{array}{l}\text { Epistemologia da } \\
\text { Ciência } \\
- \\
\text { Física newtonia- } \\
\text { na }^{15}\end{array}$ & $\begin{array}{c}\text { Apresentar o perí- } \\
\text { odo de desenvol- } \\
\text { vimento da física } \\
\text { newtoniana como } \\
\text { um instrumento } \\
\text { epistemológico e } \\
\text { histórico para a } \\
\text { contraposição de } \\
\text { concepções pro- } \\
\text { blemáticas sobre a } \\
\text { ciência } \\
\end{array}$ & $\begin{array}{l}\text { Textos elabo- } \\
\text { rados pelo } \\
\text { próprio autor. }\end{array}$ & $\begin{array}{l}\text { Formação de } \\
\text { professores } \\
- \\
\text { Não especifi- } \\
\text { cou }\end{array}$ & Não especificado. \\
\hline 15 & $\begin{array}{l}\text { Eletromagnetis- } \\
\text { mo } \\
- \\
\text { Ondas eletro- } \\
\text { magnéticas }\end{array}$ & $\begin{array}{l}\text { Aproximar o ensi- } \\
\text { no de física e a } \\
\text { tecnologia, fomen- } \\
\text { tar questões rela- } \\
\text { cionadas a NdC; } \\
\text { mudança concei- } \\
\text { tual } \\
\end{array}$ & $\begin{array}{l}\text { Livro paradi- } \\
\text { dático }\end{array}$ & $\begin{array}{l}\text { Ensino Mé- } \\
\text { dio } \\
- \\
20 \text { horas }^{16}\end{array}$ & $\begin{array}{c}\text { Leitura e discussão de } \\
\text { textos, pesquisa guiada, } \\
\text { construção de aparato } \\
\text { experimental (Arco de } \\
\text { Poulsen) e jornada cientí- } \\
\text { fica }\end{array}$ \\
\hline 16 & $\begin{array}{c}\text { Ótica } \\
- \\
\text { Modelos do pro- } \\
\text { cesso da visão }\end{array}$ & $\begin{array}{l}\text { Compreensão de } \\
\text { conceitos da ópti- } \\
\text { ca e problematizar } \\
\text { aspectos sobre a }\end{array}$ & $\begin{array}{l}\text { Textos elabo- } \\
\text { rados pelo } \\
\text { próprio autor }\end{array}$ & $\begin{array}{l}\text { Ensino médio } \\
- \\
\text { Não especifi- } \\
\text { cou }\end{array}$ & $\begin{array}{c}\text { Leitura/Resolução de } \\
\text { questões/Atividade expe- } \\
\text { rimental/Filme/ }\end{array}$ \\
\hline
\end{tabular}

13 O trabalho em questão procurou discutir a importância de uma abordagem filosófica da Ciência na graduação em física. Para tanto, abordou temas ligados ao estudo da epistemologia, por exemplo, o papel da experimentação na construção do conhecimento cientifico e o critério de validação das teorias científicas e sua mudança ao longo da história.

$14 \mathrm{O}$ autor elaborou um paradidático para o minicurso: Há Filosofia na Física!? Uma introdução de Filosofia para graduandos em ciências.

15 Por se tratar de um trabalho que discute aspectos epistemológicos da física newtoniana o autor apresenta discussões que abordam questões referentes de toda obra de Newton (Mecânica, Óptica e Gravitação).

16 A proposta foi desenvolvida ao longo do desenvolvimento de atividades para a jornada de iniciação científica, que contou com 10 (dez) encontros de duas horas, cada. Além destes encontros, ocorreu ama exposição no decorrer da jornada científica, que representa a culminância do trabalho desenvolvimento nestes encontros. 


\begin{tabular}{|c|c|c|c|c|c|}
\hline 麁 & $\begin{array}{c}\text { Temática } \\
\text { - } \\
\text { Conteúdo Histó- } \\
\text { rico }\end{array}$ & $\begin{array}{l}\text { Objetivos Peda- } \\
\text { gógicos }\end{array}$ & $\begin{array}{l}\text { Fontes dos } \\
\text { Textos }\end{array}$ & $\begin{array}{c}\text { Nível de } \\
\text { Ensino } \\
\text { - } \\
\text { Duração de } \\
\text { Aplicação } 5 \\
\end{array}$ & Estratégias de Ensino \\
\hline & & $\mathrm{NdC}$ & & & \\
\hline 17 & $\begin{array}{l}\text { Ondas (Som) } \\
- \\
\text { Acústica Renas- } \\
\text { centista. }\end{array}$ & $\begin{array}{l}\text { Compreender sob } \\
\text { uma perspectiva } \\
\text { histórico- } \\
\text { epistemológica o } \\
\text { desenvolvimento } \\
\text { da acústica musi- } \\
\text { cal no Renasci- } \\
\text { mento } \\
\end{array}$ & $\begin{array}{l}\text { Não especifi- } \\
\text { cado. }\end{array}$ & $\begin{array}{l}\text { Ensino Mé- } \\
\text { dio } \\
- \\
\text { Não especifi- } \\
\text { cado. }\end{array}$ & $\begin{array}{c}\text { Aula expositi- } \\
\text { va/Software/Construção de } \\
\text { instrumentos musicais de } \\
\text { baixo custo/Leitura de } \\
\text { textos/Experimentos }\end{array}$ \\
\hline 18 & $\begin{array}{l}\text { Astronomia } \\
- \\
\text { Cosmologia } \\
\text { Moderna }\end{array}$ & $\begin{array}{l}\text { Aproximar aspec- } \\
\text { tos da HFC do } \\
\text { ensino de física, } \\
\text { possibilitando um } \\
\text { ensino mais com- } \\
\text { prometido com a } \\
\text { NdC }\end{array}$ & $\begin{array}{l}\text { Texto elabora- } \\
\text { do pelo pró- } \\
\text { prio autor }\end{array}$ & $\begin{array}{l}\text { Formação de } \\
\text { professores } \\
- \\
\text { Não especifi- } \\
\text { cou }\end{array}$ & $\begin{array}{l}\text { Leituras dos textos, aula } \\
\text { expositiva, seminários e } \\
\text { apresentação eletrônica }\end{array}$ \\
\hline 19 & $\begin{array}{c}\text { Ótica } \\
- \\
\text { Modelo de Huy- } \\
\text { gens }\end{array}$ & $\begin{array}{l}\text { Discutir aspectos } \\
\text { do modelo ondula- } \\
\text { tório de Huygens } \\
\text { que conduzem à } \\
\text { construção do } \\
\text { modelo atual de } \\
\text { ondas }\end{array}$ & $\begin{array}{l}\text { Textos elabo- } \\
\text { rados pelo } \\
\text { próprio autor }\end{array}$ & $\begin{array}{l}\text { Formação de } \\
\text { professores } \\
- \\
\text { Não especifi- } \\
\text { cou }\end{array}$ & Não especificado \\
\hline 20 & $\begin{array}{c}\text { Física Moderna } \\
- \\
\text { Evolução do } \\
\text { Conceito de } \\
\text { Energia }\end{array}$ & $\begin{array}{l}\text { Compreensão do } \\
\text { desenvolvimento } \\
\text { histórico do con- } \\
\text { ceito de ener- } \\
\text { gia/Apresentar a } \\
\text { ciência como uma } \\
\text { atividade humana }\end{array}$ & $\begin{array}{l}\text { Texto elabora- } \\
\text { do pelo au- } \\
\text { tor/Textos } \\
\text { historiográfi- } \\
\quad \text { cos }\end{array}$ & $\begin{array}{c}\text { Ensino médio } \\
- \\
5 \text { horas }\end{array}$ & $\begin{array}{l}\text { Leitura de textos/Aula } \\
\text { expositi- } \\
\text { va/Simulação/Filme/Jogo } \\
\text { (O Dominó da Energia) }\end{array}$ \\
\hline 21 & $\begin{array}{c}\text { Mecânica } \\
- \\
\text { Gravitação New- } \\
\text { toniana e Einstei- } \\
\text { niana }\end{array}$ & $\begin{array}{l}\text { Melhorar a com- } \\
\text { preensão da Natu- } \\
\text { reza da Ciência e } \\
\text { do processo histó- } \\
\text { rico de construção } \\
\text { das teorias e con- } \\
\text { ceitos científicos } \\
\text { de futuros profes- } \\
\text { sores }\end{array}$ & $\begin{array}{l}\text { Livros didáti- } \\
\text { cos/Textos } \\
\text { historiográfi- } \\
\text { cos (livros e } \\
\text { artigos). }\end{array}$ & $\begin{array}{c}\text { Formação de } \\
\text { professores } \\
- \\
20 \text { horas-aula }\end{array}$ & $\begin{array}{c}\text { Apresentação dialoga- } \\
\text { da/Discussão dos tex- } \\
\text { tos/Questão proble- } \\
\text { ma/Avaliação escri- } \\
\text { ta/Exibição de documentá- } \\
\text { rio }\end{array}$ \\
\hline 22 & $\begin{array}{c}\text { Astronomia } \\
- \\
\text { Cosmologia } \\
\text { (Controvérsia } \\
\text { entra a teoria do } \\
\text { Big Bang e o } \\
\text { Estado Estacio- } \\
\text { nário) } \\
\end{array}$ & $\begin{array}{l}\text { Fornecer subsídios } \\
\text { para o ensino de } \\
\text { Cosmolo- } \\
\text { gia/Discutir certos } \\
\text { aspectos sobre } \\
\text { NdC }\end{array}$ & $\begin{array}{l}\text { Fonte secun- } \\
\text { dária }^{17}\end{array}$ & $\begin{array}{c}\begin{array}{c}\text { Formação de } \\
\text { professores } \\
-\end{array} \\
10 \text { horas-aula }\end{array}$ & $\begin{array}{l}\text { Aulas expositivas dialoga- } \\
\text { da/Leitura de tex- } \\
\text { tos/Debates/Apresentação } \\
\text { de seminários/Realização } \\
\text { de uma peça de tea- } \\
\text { tro/Exibição de documen- } \\
\text { tário }\end{array}$ \\
\hline 23 & $\begin{array}{c}\text { Física Moderna } \\
\text { - } \\
\text { Radioatividade }\end{array}$ & $\begin{array}{l}\text { Analisar a trans- } \\
\text { posição didática } \\
\text { operada sobre o }\end{array}$ & $\begin{array}{l}\text { Textos elabo- } \\
\text { rados pela } \\
\text { própria autora }\end{array}$ & $\begin{array}{l}\text { Formação de } \\
\text { professores } \\
-\end{array}$ & $\begin{array}{l}\text { Aula expositiva/Leitura de } \\
\text { textos/Debates }\end{array}$ \\
\hline
\end{tabular}

${ }^{17}$ Big Bang Brasil. Adaptado de Ceticismo, Ciência e Tecnologia (NOGUEIRA, 2007). 


\begin{tabular}{|c|c|c|c|c|c|}
\hline 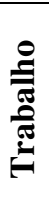 & $\begin{array}{c}\text { Temática } \\
\text { - } \\
\text { Conteúdo Histó- } \\
\text { rico }\end{array}$ & $\begin{array}{l}\text { Objetivos Peda- } \\
\text { gógicos }\end{array}$ & $\begin{array}{l}\text { Fontes dos } \\
\text { Textos }\end{array}$ & $\begin{array}{c}\text { Nível de } \\
\text { Ensino } \\
\text { - } \\
\text { Duração de } \\
\text { Aplicação } 5\end{array}$ & Estratégias de Ensino \\
\hline & & $\begin{array}{l}\text { fenômeno da radi- } \\
\text { oatividade e suas } \\
\text { consequências } \\
\text { para o ensino }\end{array}$ & & 6 horas-aula & \\
\hline 24 & $\begin{array}{c}\text { Mecânica } \\
- \\
\text { Velocida- } \\
\text { de/Força }^{18}\end{array}$ & $\begin{array}{l}\text { Conceitos científi- } \\
\text { cos relacionados a } \\
\text { mecânica }\end{array}$ & $\begin{array}{l}\text { Textos elabo- } \\
\text { rados pelo } \\
\text { próprio autor }\end{array}$ & $\begin{array}{c}\text { Ensino médio } \\
- \\
\text { Ano letivo }\end{array}$ & $\begin{array}{l}\text { Leitura dos textos, discus- } \\
\text { são em sala }\end{array}$ \\
\hline 25 & $\begin{array}{c}\text { Ótica } \\
- \\
\text { Conflito entre a } \\
\text { teoria corpuscu- } \\
\text { lar e ondulatória }\end{array}$ & $\begin{array}{c}\text { Avaliar a utiliza- } \\
\text { ção de Textos } \\
\text { Originais de Cien- } \\
\text { tistas (TOC) e } \\
\text { Textos sobre a } \\
\text { História das Ideias } \\
\text { da Ciência (THIC) } \\
\text { no Ensino de Físi- } \\
\text { ca }\end{array}$ & $\begin{array}{l}\text { Fontes primá- } \\
\text { rias e secundá- } \\
\text { rias }\end{array}$ & $\begin{array}{c}\text { Formação de } \\
\text { professores } \\
- \\
9 \text { Aulas }\end{array}$ & $\begin{array}{c}\text { Aulas expositivas dialoga- } \\
\text { das/Leitura de tex- } \\
\text { tos/Discussão em sala }\end{array}$ \\
\hline 26 & $\begin{array}{c}\text { Óti- } \\
\text { ca/Eletromagneti } \\
\text { smo } \\
- \\
\text { História da Ótica } \\
\text { e do Eletromag- } \\
\text { netismo }\end{array}$ & $\begin{array}{l}\text { Desenvolver a } \\
\text { formação crítico- } \\
\text { transformadora a } \\
\text { partir de uma } \\
\text { visão mais clara } \\
\text { do processo de } \\
\text { construção do } \\
\text { conhecimento } \\
\text { científico } \\
\end{array}$ & $\begin{array}{l}\text { Textos elabo- } \\
\text { rados pelo } \\
\text { autor }\end{array}$ & $\begin{array}{c}\text { Formação de } \\
\text { professores } \\
- \\
30 \text { horas-aula }\end{array}$ & $\begin{array}{l}\text { Leitura de textos, discus- } \\
\text { sões, análise experimental, } \\
\text { aulas expositivas, proble- } \\
\text { matização e elaboração de } \\
\text { material didático }\end{array}$ \\
\hline 27 & $\begin{array}{c}\text { Física Moderna e } \\
\text { Contemporânea } \\
- \\
\text { Cosmologia }\end{array}$ & $\begin{array}{l}\text { Discutir e proble- } \\
\text { matizar questões } \\
\text { sobre a Natureza } \\
\text { da Ciência }\end{array}$ & $\begin{array}{l}\text { Textos elabo- } \\
\text { rados pelo } \\
\text { próprio au- } \\
\text { tor/Textos } \\
\text { historiográfi- } \\
\text { cos } \\
\end{array}$ & $\begin{array}{c}\text { Formação de } \\
\text { professores } \\
- \\
12 \text { horas-aula }\end{array}$ & $\begin{array}{l}\text { Aulas expositivas dialoga- } \\
\text { das/Leitura de tex- } \\
\text { tos/Recursos áudios- } \\
\text { visuais (imagens, simula- } \\
\text { ções e vídeos) }\end{array}$ \\
\hline 28 & Energia & $\begin{array}{l}\text { Uso de narrativas } \\
\text { histórias para } \\
\text { discutir concep- } \\
\text { ções sobre Nature- } \\
\text { za da Ciência } \\
\end{array}$ & $\begin{array}{l}\text { Narrativas } \\
\text { histórias de- } \\
\text { senvolvidas } \\
\text { pelo próprio } \\
\text { autor } \\
\end{array}$ & $\begin{array}{l}\text { Ensino fun- } \\
\text { damental } \\
- \\
8 \text { horas-aula }\end{array}$ & $\begin{array}{l}\text { Aulas expositivas dialoga- } \\
\text { das/Elaboração de ques- } \\
\text { tões/Questionário/Recurso } \\
\text { s audiovisuais (imagens, } \\
\text { fotos, simulações, vídeos) }\end{array}$ \\
\hline 29 & $\begin{array}{c}\text { Ótica } \\
\text { - } \\
\text { Luz e Visão }\end{array}$ & $\begin{array}{l}\text { Inserir a discussão } \\
\text { de elementos de } \\
\text { Natureza da Ciên- } \\
\text { cia a partir do uso } \\
\text { da HC/Gerar } \\
\text { aprendizagem de } \\
\text { conceitos sobre } \\
\text { luz e visão }\end{array}$ & $\begin{array}{l}\text { Fontes secun- } \\
\text { dárias }\end{array}$ & $\begin{array}{c}\text { Ensino médio } \\
\text { - } \\
10 \text { horas-aula }\end{array}$ & $\begin{array}{l}\text { Leitura de textos/ Aulas } \\
\text { expositivas dialogadas } \\
\text { /Discussão de tex- } \\
\text { tos/Atividades experimen- } \\
\text { tais }\end{array}$ \\
\hline 30 & $\begin{array}{l}\text { História do Vá- } \\
\text { cuo }\end{array}$ & $\begin{array}{l}\text { Discutir o uso } \\
\text { didático da abor- } \\
\text { dagem histórico- } \\
\text { filosófi- }\end{array}$ & $\begin{array}{l}\text { Textos histori- } \\
\text { ográfi- } \\
\text { cos/Trecho de } \\
\text { fontes primá- }\end{array}$ & $\begin{array}{c}\text { Formação de } \\
\text { professores } \\
- \\
17 \text { horas-aula }\end{array}$ & $\begin{array}{l}\text { Leitura e discussão de } \\
\text { textos/ Aulas expositivas } \\
\text { dialogadas/Debate }\end{array}$ \\
\hline
\end{tabular}

\footnotetext{
$18 \mathrm{O}$ autor discutiu aspectos da História e Filosofia da Ciência em meio aos assuntos da mecânica, dando ênfase aos aspectos relacionados à velocidade e força.
} 


\begin{tabular}{|c|c|c|c|c|c|}
\hline 里 & $\begin{array}{c}\text { Temática } \\
\text { - } \\
\text { Conteúdo Histó- } \\
\text { rico }\end{array}$ & $\begin{array}{l}\text { Objetivos Peda- } \\
\text { gógicos }\end{array}$ & $\begin{array}{l}\text { Fontes dos } \\
\text { Textos }\end{array}$ & $\begin{array}{c}\text { Nível de } \\
\text { Ensino } \\
\text { - } \\
\text { Duração de } \\
\text { Aplicação } 5 \\
\end{array}$ & Estratégias de Ensino \\
\hline & & $\begin{array}{l}\text { ca/Problematizar } \\
\text { explicitamente } \\
\text { conteúdos de Na- } \\
\text { tureza da Ciên- } \\
\text { cia/Orientar e } \\
\text { discutir a elabora- } \\
\text { ção de propostas } \\
\text { voltas para o ensi- } \\
\text { no médio }\end{array}$ & rias & & \\
\hline 31 & $\begin{array}{c}\text { Física Moderna e } \\
\text { Contemporânea } \\
- \\
\text { Radioatividade }\end{array}$ & $\begin{array}{c}\text { Promover apren- } \\
\text { dizagem dos con- } \\
\text { teúdos conceitu- } \\
\text { ais/Debater às } \\
\text { consequências da } \\
\text { radiação nucle- } \\
\text { ar/Promover inte- } \\
\text { ração entre profes- } \\
\text { sores e alu- } \\
\text { nos/Contribuir } \\
\text { para a formação de } \\
\text { cidadãos compro- } \\
\text { missados com } \\
\text { questões sociais }\end{array}$ & $\begin{array}{l}\text { Textos elabo- } \\
\text { rados pelo } \\
\text { próprio autor }\end{array}$ & $\begin{array}{l}\text { Ensino médio } \\
- \\
8 \text { horas-aula }\end{array}$ & $\begin{array}{l}\text { Aulas expositivas dialoga- } \\
\text { das/Leitura e discussão de } \\
\text { textos/Debate de situação } \\
\text { problema/Mapas conceitu- } \\
\text { ais/ Recursos audiovisuais } \\
\text { (vídeos; ima- } \\
\text { gens/simulações) }\end{array}$ \\
\hline 32 & $\begin{array}{c}\text { Termodinâmica } \\
- \\
\text { Relação entre } \\
\text { calor e energia }\end{array}$ & $\begin{array}{l}\text { Promover a dis- } \\
\text { cussão e a reflexão } \\
\text { de alguns aspectos } \\
\text { relacionados a } \\
\text { Natureza da Ciên- } \\
\text { cia utilizando a } \\
\text { HC } \\
\end{array}$ & $\begin{array}{l}\text { Fontes primá- } \\
\text { rias/Fontes } \\
\text { secundá- } \\
\text { rias/Textos } \\
\text { elaborados } \\
\text { pelo autor }\end{array}$ & $\begin{array}{l}\text { Ensino médio } \\
- \\
6 \text { horas-aula }\end{array}$ & $\begin{array}{l}\text { Aulas discursivas/Leitura e } \\
\text { discussão de tex- } \\
\text { tos/Problematização/ Re- } \\
\text { cursos audiovisuais (ví- } \\
\text { deos; slides) }\end{array}$ \\
\hline 33 & $\begin{array}{c}\text { Mecânica } \\
- \\
\text { Inércia }\end{array}$ & $\begin{array}{l}\text { Ensinar o conceito } \\
\text { de inércia e discu- } \\
\text { tir conteúdos sele- } \\
\text { cionados de Natu- } \\
\text { reza da Ciência }\end{array}$ & $\begin{array}{l}\text { Textos elabo- } \\
\text { rados pelo } \\
\text { próprio au- } \\
\text { tor/Textos } \\
\text { historiográfi- } \\
\text { cos } \\
\end{array}$ & $\begin{array}{c}\text { Formação de } \\
\text { professores } \\
- \\
8 \text { horas-aula }\end{array}$ & $\begin{array}{l}\text { Aulas discursivas/Leitura e } \\
\text { discussão de textos/ Re- } \\
\text { cursos audiovisuais (ví- } \\
\text { deos; slides) }\end{array}$ \\
\hline 34 & $\begin{array}{c}\text { Ótica/Física } \\
\text { Moderna } \\
- \\
\text { Evolução históri- } \\
\text { ca do conceito de } \\
\text { luz } \\
\end{array}$ & $\begin{array}{l}\text { Utilizar a aborda- } \\
\text { gem histórica para } \\
\text { discutir a evolução } \\
\text { do conceito de luz }\end{array}$ & $\begin{array}{l}\text { Não especifi- } \\
\text { cado }\end{array}$ & $\begin{array}{c}\text { Ensino médio } \\
- \\
21 \text { aulas } 19\end{array}$ & $\begin{array}{c}\text { Aula expositi- } \\
\text { va/Demonstrações expe- } \\
\text { rimen- } \\
\text { tais/Exercícios/Slides }\end{array}$ \\
\hline 35 & $\begin{array}{c}\text { Física Moderna e } \\
\text { Contemporânea } \\
- \\
\text { Energia nuclear }\end{array}$ & $\begin{array}{l}\text { Problematizar } \\
\text { elementos da Na- } \\
\text { tureza da Ciên- } \\
\text { cia/Aprendizagem } \\
\text { colaborativa } \\
\end{array}$ & $\begin{array}{l}\text { Texto histori- } \\
\text { ográfico }\end{array}$ & $\begin{array}{c}\text { Ensino médio } \\
- \\
6 \text { aulas }^{20}\end{array}$ & Aula expositiva e prática \\
\hline 36 & Espaço e Tempo & Problematizar os & Textos elabo- & Ensino médio & Aula expositiva/Pesquisa \\
\hline
\end{tabular}

\footnotetext{
19 O autor não especificou a duração de cada aula.

${ }^{20}$ Cada aula possui uma duração de 30 minutos.
} 


\begin{tabular}{|c|c|c|c|c|c|}
\hline 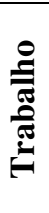 & $\begin{array}{c}\text { Temática } \\
\text { - } \\
\text { Conteúdo Histó- } \\
\text { rico }\end{array}$ & $\begin{array}{l}\text { Objetivos Peda- } \\
\text { gógicos }\end{array}$ & $\begin{array}{l}\text { Fontes dos } \\
\text { Textos }\end{array}$ & $\begin{array}{c}\text { Nível de } \\
\text { Ensino } \\
\text { - } \\
\text { Duração de } \\
\text { Aplicação } 5\end{array}$ & Estratégias de Ensino \\
\hline & & $\begin{array}{l}\text { conceitos de espa- } \\
\text { ço e tempo }\end{array}$ & $\begin{array}{l}\text { rados pelo } \\
\text { próprio autor }\end{array}$ & 36 horas-aula & $\begin{array}{c}\text { guiada/Leitura e discussão } \\
\text { de texto/Resolução de } \\
\text { questões/Produção de } \\
\text { desenhos e histórias em } \\
\text { quadrinhos/Produção de } \\
\text { vídeo/Vídeo aulas/Slides }\end{array}$ \\
\hline 37 & $\begin{array}{c}\text { Física Moderna e } \\
\text { Contemporânea } \\
- \\
\text { Efeito fotoelétri- } \\
\text { co/Natureza da } \\
\text { luz }\end{array}$ & $\begin{array}{l}\text { Discutir questões } \\
\text { referentes a Natu- } \\
\text { reza da Ciência a } \\
\text { partir do uso didá- } \\
\text { tico da História da } \\
\text { Ciência }\end{array}$ & $\begin{array}{l}\text { Textos elabo- } \\
\text { rados pelo } \\
\text { autor }\end{array}$ & $\begin{array}{l}\text { Ensino médio } \\
- \\
8 \text { horas-aula }\end{array}$ & $\begin{array}{c}\text { Aulas discursivas/Leitura e } \\
\text { discussão de tex- } \\
\text { tos/Resolução de ques- } \\
\text { tões/Apresentação de ex- } \\
\text { perimentos } \\
\text { Recursos audiovisuais } \\
\text { (simulação; slides) }\end{array}$ \\
\hline 38 & $\begin{array}{l}\text { Do Geocentrismo } \\
\text { à Gravitação } \\
\text { Universal }\end{array}$ & $\begin{array}{l}\text { Desenvolvimento } \\
\text { de uma visão } \\
\text { adequada sobre a } \\
\text { Natureza da Ciên- } \\
\text { cia/Aprendizagem } \\
\text { de conceitos cien- } \\
\text { tíficos } \\
\end{array}$ & $\begin{array}{l}\text { Textos histori- } \\
\text { ográficos }\end{array}$ & $\begin{array}{l}\text { Ensino médio } \\
- \\
\text { Não especifi- } \\
\text { cado }\end{array}$ & $\begin{array}{c}\text { Leitura e discussão de } \\
\text { tex- } \\
\text { tos/Modelização/Produção } \\
\text { de tex- } \\
\text { to/Encenação/Recurso } \\
\text { audiovisuais (Software; } \\
\text { simulação; vídeo) }\end{array}$ \\
\hline 39 & $\begin{array}{c}\text { Mecânica } \\
- \\
\text { Movimento de } \\
\text { queda dos corpos }\end{array}$ & $\begin{array}{c}\text { Mapear e discutir } \\
\text { concepções sobre } \\
\text { Natureza da Ciên- } \\
\text { cia e o movimento } \\
\text { de queda dos cor- } \\
\text { pos/Desenvolver a } \\
\text { habilidade de } \\
\text { argumentar }\end{array}$ & $\begin{array}{l}\text { Textos elabo- } \\
\text { rados pelo } \\
\text { autor e histo- } \\
\text { riográficos }\end{array}$ & $\begin{array}{l}\text { Ensino fun- } \\
\text { damental } \\
- \\
7 \text { (sete) en- } \\
\text { contros }^{21}\end{array}$ & $\begin{array}{c}\text { Leitura e discussão de } \\
\text { textos/Debates/Julgamento } \\
\text { simulado/Resolução de } \\
\text { questões/vídeos }\end{array}$ \\
\hline 40 & $\begin{array}{c}\text { Física Moderna e } \\
\text { Contemporânea } \\
- \\
\text { Teoria da Relati- } \\
\text { vidade Restrita }\end{array}$ & $\begin{array}{l}\text { Ensino da Teoria } \\
\text { da relatividade } \\
\text { Restrita/Promover } \\
\text { a construção de } \\
\text { esquemas para a } \\
\text { aprendizagem de } \\
\text { conceitos científi- } \\
\text { cos }\end{array}$ & $\begin{array}{l}\text { Textos elabo- } \\
\text { rados pelo } \\
\text { autor }\end{array}$ & $\begin{array}{l}\text { Ensino médio } \\
\text { - } \\
20 \text { horas-aula }\end{array}$ & $\begin{array}{l}\text { Leitura e discussão de } \\
\text { textos/Aulas expositivas } \\
\text { dialogadas/Resolução de } \\
\text { questões/Recursos audio- } \\
\text { visuais (Slides; simulação) }\end{array}$ \\
\hline 41 & $\begin{array}{c}\text { Mecânica } \\
- \\
\text { Conceito de For- } \\
\text { ça }\end{array}$ & $\begin{array}{l}\text { A partir do desen- } \\
\text { volvimento do } \\
\text { conceito de força, } \\
\text { estabelecer pro- } \\
\text { cessos de aprendi- } \\
\text { zagem a partir de } \\
\text { uma interação } \\
\text { social } \\
\end{array}$ & $\begin{array}{l}\text { Texto elabora- } \\
\text { do pelo autor }\end{array}$ & $\begin{array}{c}\text { Ensino médio } \\
- \\
7 \text { horas-aula }\end{array}$ & $\begin{array}{l}\text { Leitura de tex- } \\
\text { to/Debate/Aula expositi- } \\
\text { va/Apresentações coletivas }\end{array}$ \\
\hline 42 & $\begin{array}{c}\text { Mecânica } \\
- \\
\text { Gravitação Uni- } \\
\text { versal }\end{array}$ & $\begin{array}{c}\text { Desenvolver a } \\
\text { habilidade de } \\
\text { argumentação e } \\
\text { compreensão } \\
\text { sobre a Gravitação }\end{array}$ & $\begin{array}{l}\text { Texto elabora- } \\
\text { do pelo au- } \\
\text { tor/Texto } \\
\text { historiográfico }\end{array}$ & $\begin{array}{c}\text { Formação de } \\
\text { professores } \\
- \\
13 \text { horas-aula }\end{array}$ & $\begin{array}{l}\text { Leitura e discussão de } \\
\text { textos/Resolução de pro- } \\
\text { blemas/Construção de } \\
\text { argumentos }\end{array}$ \\
\hline
\end{tabular}

\footnotetext{
21 A proposta foi desenvolvida e aplicada em formato de oficina, no horário oposto às aulas regulares, sendo dividida em sete encontros de 100 minutos cada.
} 


\begin{tabular}{|c|c|c|c|c|c|}
\hline 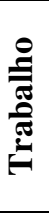 & $\begin{array}{l}\text { Temática } \\
\text { - } \\
\text { Conteúdo Histó- } \\
\text { rico }\end{array}$ & $\begin{array}{l}\text { Objetivos Peda- } \\
\text { gógicos }\end{array}$ & $\begin{array}{l}\text { Fontes dos } \\
\text { Textos }\end{array}$ & $\begin{array}{c}\text { Nível de } \\
\text { Ensino } \\
\text { - } \\
\text { Duração de } \\
\text { Aplicação } 5\end{array}$ & Estratégias de Ensino \\
\hline & & $\begin{array}{l}\text { Universal de New- } \\
\text { ton }\end{array}$ & & & \\
\hline 43 & $\begin{array}{l}\text { Pressão atmosfé- } \\
\text { rica }\end{array}$ & $\begin{array}{l}\text { Compreensão } \\
\text { histórica do con- } \\
\text { ceito de pressão } \\
\text { atmosférica e a } \\
\text { discussão de tópi- } \\
\text { cos relacionados à } \\
\text { Natureza da Ciên- } \\
\text { cia por meio do } \\
\text { uso de fontes } \\
\text { primárias }\end{array}$ & $\begin{array}{l}\text { Fontes primá- } \\
\text { rias/Textos } \\
\text { historiográfi- } \\
\text { cos/Livro } \\
\text { didático }\end{array}$ & $\begin{array}{c}\text { Ensino médio } \\
- \\
4 \text { (quatro) } \\
\text { momentos }^{22}\end{array}$ & $\begin{array}{c}\text { Leitura e discussão de } \\
\text { texto/Aula expositiva } \\
\text { dialógi- } \\
\text { ca/Experimentação/Resolu } \\
\text { ção de questões }\end{array}$ \\
\hline
\end{tabular}

Fonte: Elaborada pelos autores da pesquisa.

O quadro 3 apresenta uma caracterização geral das propostas didáticas selecionadas, porém, com o objetivo de elaborar uma melhor compreensão sobre os aspectos descritos neste quadro, será realizada uma análise geral de todas as características destacadas ao longo do mesmo.

\section{III.2 Temática/Conteúdo Histórico Abordado}

A partir da análise geral das propostas didáticas, foi constatado que um número significativo de trabalhos aborda assuntos de Mecânica Clássica (30\%), Ótica (16\%), e Física Moderna (21\%). Algumas abordam às seguintes temáticas: Astronomia (7\%) e Termodinâmica/Eletromagnetismo (9\%). As demais propostas utilizam temáticas diversas, como Epistemologia, Ondas, Energia, Espaço e tempo, Pressão atmosférica e História do Vácuo, que ao todo representam $17 \%$ das propostas didáticas de física selecionadas.

Ao apresentar o estado da arte das pesquisas que investigam intervenções didáticas orientadas por abordagens históricas, publicados em revistas especializadas da área, Teixeira et al. (2012a; 2012b), destacam grande predominância de trabalhos que tratam de Mecânica Clássica no Brasil (43\%), e forte incidência de trabalhos que abordam ótica clássica no cenário internacional $(45 \%)^{23}$. Para esses autores, a escassez de aspectos de FMC nas propostas didáticas de física orientadas por abordagens históricas, publicados em revistas especializadas da área, está, também, relacionada a uma tradição na área de EF no Brasil e no mundo, cuja predominância de trabalhos que abordam assuntos sobre a Mecânica Clássica é grande. Característica que reflete o excesso de mecânica clássica nos livros didáticos, nos programas do

\footnotetext{
$22 \mathrm{O}$ curso foi aplicado em quatro momentos num formato de minicurso, porém não foi específico a duração de cada encontro.

${ }^{23}$ No cenário brasileiro foram analisados 14 trabalhos e 11 no cenário internacional.
} 
ensino médio e nos processos seletivos para ingresso nas instituições de ensino superior (AZEVEDO et al., 2009).

Gráfico 2: Distribuição por assunto, das propostas didáticas selecionadas (total = 43 propostas).

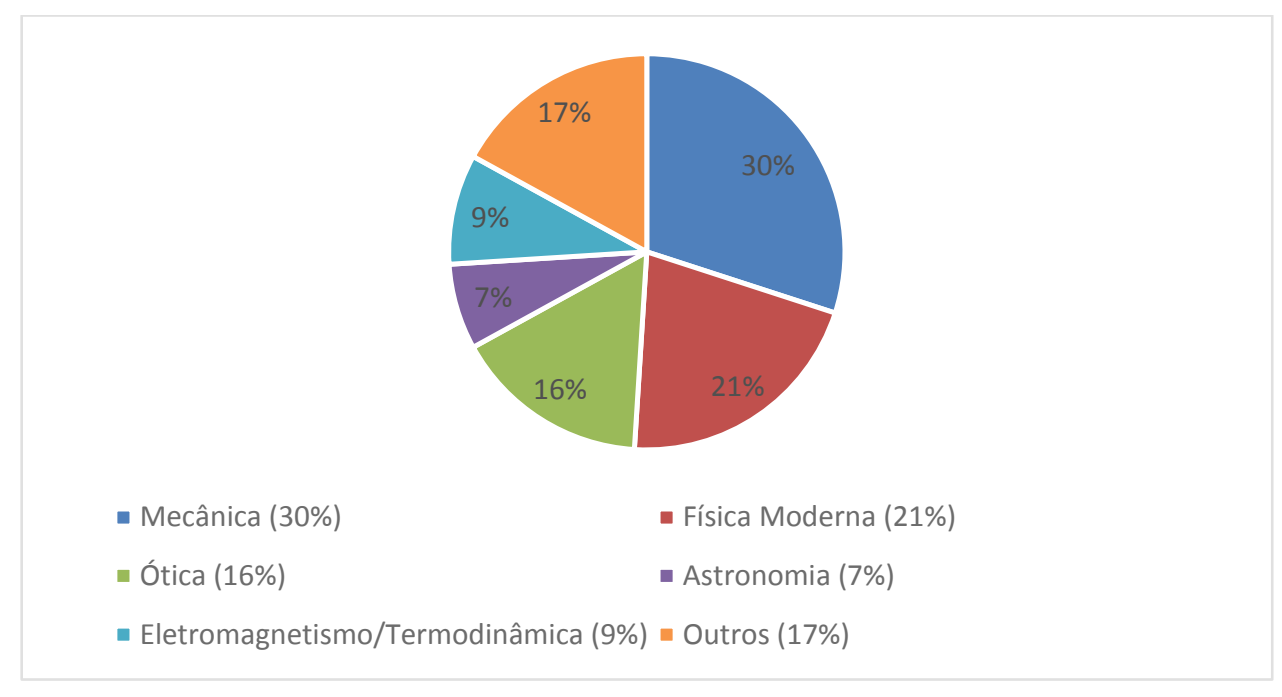

Fonte: elaborado pelo autor da pesquisa.

Diferente dos resultados encontrados por Teixeira et al. (2012a; 2012b), a análise das propostas didáticas de física, orientadas por abordagens históricas, defendidas nos programas de pós-graduação da área, identificou um número significativo de propostas que abordam assuntos relacionados a FMC (21\%). Resultado que reflete uma tendência defendida por professores e pesquisadores sobre a relevância de inserção da FMC no currículo da Educação Básica (NETO; CAVALCANTE; OSTERMANN, 2015).

\section{III.3 Objetivos pedagógicos}

Os objetivos pedagógicos que se deseja alcançar com a utilização da abordagem histórica no EF, definidos pelas propostas analisadas, são variados: relação entre Ciência e Tecnologia, promover o aprendizado de conceitos, utilizar a HC no ensino, desenvolver a habilidade de argumentar, entre outros. Contudo, existem trabalhos em que os objetivos pedagógicos se sobrepõem. 
Gráfico 3: Distribuição dos objetivos pedagógicos almejados pelas propostas didáticas selecionadas (total $=43$ propostas).

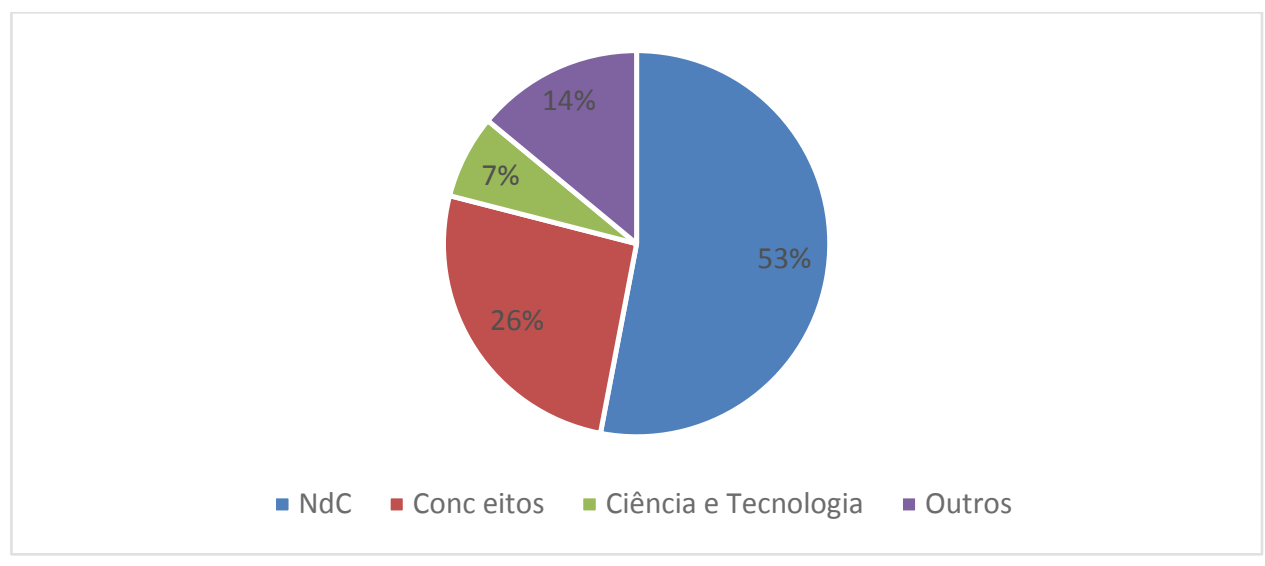

Fonte: elaborado pelo autor da pesquisa.

Entre os objetivos pedagógicos almejados pela utilização da $\mathrm{HC}$ no EF, um número significativo de propostas didáticas, aproximadamente 53\%, procura discutir aspectos sobre NdC. No cenário nacional e internacional Teixeira et al. (2012a) e Teixeira et al. (2012b), respectivamente, encontraram resultados semelhantes.

A abordagem histórica tem sido defendida, tanto por pesquisadores da área quanto pelos PCN, como uma estratégia pedagógica capaz de contribuir significativamente com o ensino de alguns aspectos sobre $\mathrm{NdC}$, ou como uma estratégia importante para melhorar a compreensão de estudantes sobre a Ciência (MATTHEWS, 1994; PEDUZZI, 2001; PAGLIARINI, 2007; FORATO, 2009, GRECA et al., 2018). Dessa forma, os resultados ilustrados acima podem evidenciar uma influência por parte de pesquisadores e documentos orientadores da educação brasileira, sobre a utilização da HC nas discussões que envolvem aspectos sobre a NdC no EF.

A partir da análise geral das temáticas abordadas pelas teses e dissertações é possível identificar o primeiro aspecto positivo das propostas didáticas de física orientadas por abordagens históricas, desenvolvidas no cenário educacional brasileiro: atender uma diversidade de objetivos pedagógicos. Isso mostra que, apesar da relevância em um número maior de intervenções empíricas para o estudo sobre as reais contribuições que a abordagem histórica traz para o ensino de ciências (TEIXEIRA et al., 2012a), os professores e pesquisadores interessados na interface entre a HFC e o EF procuram utilizar a abordagem histórica para distintos objetivos pedagógicos.

\section{III.4 Fonte dos textos utilizados}

Em meio à diversidade de objetivos pedagógicos pretendidos com a utilização didática da $\mathrm{HC}$ no EF surge o desafio de selecionar e/ou elaborar os textos que devem compor a 
proposta didática. Para isso, devem ser utilizadas fontes historiográficas desenvolvidas por especialistas da área (MARTINS, 2001; FORATO, 2009).

Os textos utilizados nas propostas didáticas selecionadas são, em sua maioria, desenvolvidos pelos próprios autores, os quais se baseiam em fontes primárias e secundárias. A proposta 13 desenvolveu um material paradidático para o minicurso que compõe a intervenção didática com o objetivo de introduzir filosofia da ciência para futuros professores de física. Enquanto que a proposta 7, desenvolveu, a partir da utilização de fontes primárias e secundárias, um livro paradidático. Esse material, entre outros aspectos, aborda questões relacionadas à filosofia da ciência a partir da discussão de problemas e experimentos históricos.

Apesar das características que se superpõem, as fontes dos textos utilizados podem ser classificadas da seguinte forma:

Gráfico 4: Distribuição dos tipos de fontes de textos, das propostas didáticas selecionadas (total $=43$ propostas).

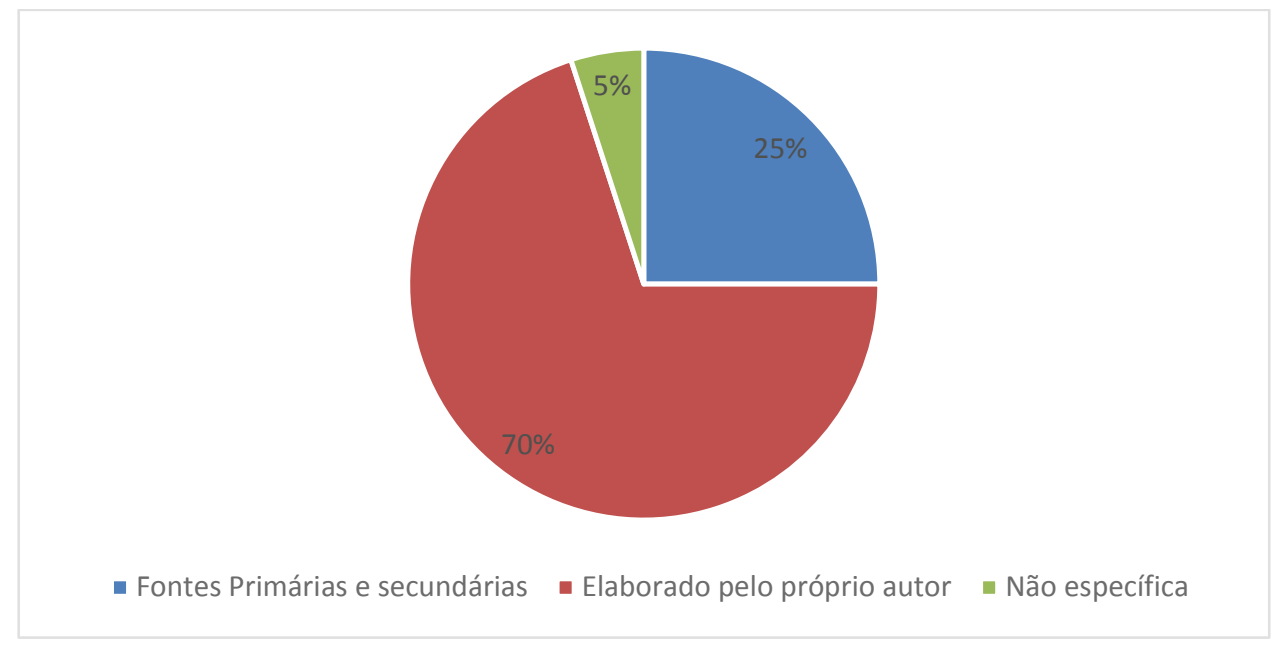

Fonte: elaborado pelo autor da pesquisa.

Um exemplo da superposição de fontes de textos utilizados é a proposta didática $\mathbf{2 1}$, que selecionou textos historiográficos e didáticos, além de elaborar um dos textos que formam o trabalho.

Aproximadamente $70 \%$ dos trabalhos selecionados utilizam em suas propostas didáticas textos históricos desenvolvidos pelos próprios autores, sendo esse um aspecto positivo das propostas didáticas selecionadas. Selecionar os textos que compõem a proposta didática é uma característica importante, diante da relevância de se produzir mais e melhores textos que favoreçam a utilização da HC no EF. Em um contexto, em que a falta de formação específica do professor para trabalhar com a abordagem histórica se configura como um desafio para a utilização da HC no EF (FORATO, 2009). 
Ao todo, 25\% dos autores optaram por usar textos escritos por especialistas, historiadores da Ciência, publicados em periódicos especializados na área de ensino de ciências, ou por profissionais de ensino que trabalham com a utilização didática da $\mathrm{HC}$ no EF. Os textos escritos por profissionais na área de ensino foram classificados como textos didáticos, que utilizam a abordagem histórica (MEDEIROS, 2001; 2002; SILVEIRA; PEDUZZI, 2006).

A falta de formação específica dos professores de física para trabalhar com a $\mathrm{HC}$ e a pouca disponibilidade de materiais didáticos que abordam a interface entre essa área e ensino de ciências são obstáculos que devem ser superados para a utilização da abordagem histórica no EF (FORATO, 2009; HÖTTECHE; SILVA, 2011). Em mais da metade dos trabalhos analisados, os autores contornaram essa última dificuldade elaborando seus próprios textos, enquanto outros utilizaram textos disponíveis em periódicos nacionais especializados na área. Portanto, essas duas características são aspectos positivos identificados durante o processo de análise.

Para a elaboração dos textos didáticos sobre a abordagem histórica, os autores das propostas utilizaram fontes primárias e secundárias, dando ênfase, nos textos didáticos, a fontes secundárias e a trechos de fontes primárias. Quando descreve a utilização das fontes em abordagens que usam HC no ensino médio, Forato (2009) argumenta que a utilização de fontes primárias em sala de aula é perigosa, pois existe o risco da realização de anacronismo.

$\mathrm{O}$ autor da proposta didática 32 utilizou trechos de fontes primárias e secundárias para tratar da relação entre calor e energia, a partir do uso didático da HC, num curso voltado para alunos do ensino médio. Portanto, apesar dos desafios e riscos, o uso de fontes primárias pode ser um recurso adotado para o uso didático da HC no EF em diferentes níveis de ensino. O uso de fontes primárias, por sua vez, deve ser acompanhado por estratégias voltadas para uma interpretação diacrônica das mesmas.

\section{III.5 Tempo de intervenção}

A relação saber/duração é fundamental para o processo didático e de grande importância para a utilização da $\mathrm{HC}$ no ensino de ciências. O tempo didático representa um desafio de cunho pedagógico e historiográfico, que depende do ambiente de ensino em que a abordagem histórica vai ser utilizada (FORATO, 2009).

Dentre as propostas selecionadas, $23 \%$ não especificam o tempo de aplicação da intervenção didática. Algumas propostas dividem o tempo de aplicação em um semestre, dois semestres, de quatro a dez horas/aula 24 e de dezesseis a trinta horas/aula. Em outros casos os autores definem por encontro, haja vista que esses trabalhos foram desenvolvidos em formato de oficinas/minicursos para serem aplicados em turno oposto ao horário regular (Propostas didáticas 39 e 43 ).

\footnotetext{
${ }^{24}$ Uma hora aula equivale, neste contexto, a uma aula de 50 minutos.
} 
Gráfico 5: Distribuição por tempo de intervenção, das propostas didáticas selecionadas (total $=43$ propostas).

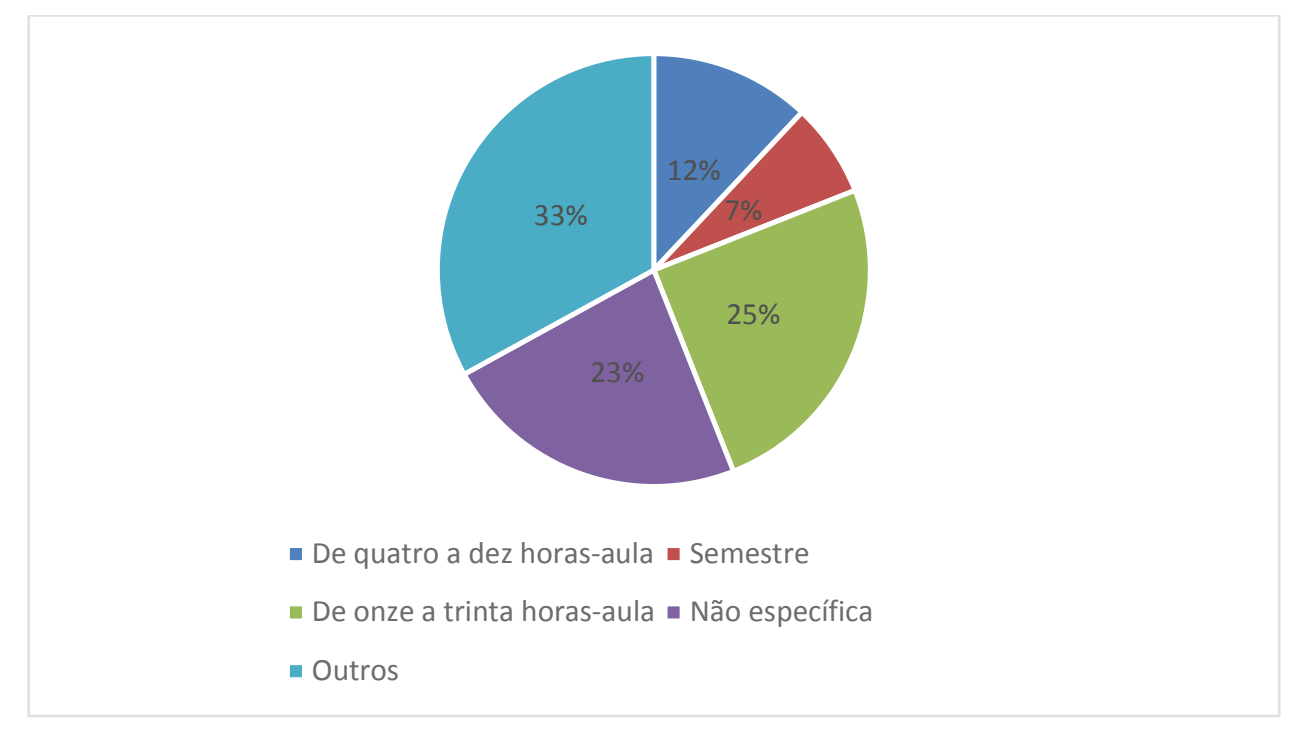

Fonte: elaborado pelo autor da pesquisa.

O trabalho 24 define o tempo de aplicação da proposta em um ano letivo, porém afirma discutir aspectos históricos em meio às discussões dos assuntos tradicionais da Mecânica, ou seja, em alguns momentos específicos, caracterizando a intervenção numa abordagem não integrada. A estratégia integrada é mais eficaz, pois discute o assunto a partir de uma forma conectada com a HC (MATTHEWS, 1994; GRECA et al., 2018). Na abordagem integrada, o assunto de física é discutido a partir da utilização da abordagem histórica, ou seja, "trata-se de apresentar o assunto por meio de uma abordagem que discute o seu surgimento e evolução histórico-conceitual" (TEIXEIRA et al., 2012b, p. 26).

Os efeitos de uma intervenção didática podem ser maiores quando o tempo de aplicação for maior, apesar de não haver uma relação direta entre o tempo de intervenção e a qualidade da mesma (TEIXEIRA et al., 2012a; 2012b). A relação saber/duração é um elemento importante para o processo didático, "pois o processo didático existe como interação de um texto e de uma duração" (CHEVALLARD, 1991, p. 75).

A divisão de aplicação da proposta depende, entre outros fatores, dos objetivos pedagógicos que se deseja alcançar bem como das características dos sujeitos inseridos no ambiente de ensino. Sendo possível adaptar uma proposta didática para diferentes ambientes de ensino. Haja vista, que o tempo de aplicação da proposta está diretamente relacionado aos objetivos pedagógicos que se deseja alcançar com a aplicação da mesma (BEZERRA, 2014).

Apresentar "um sequenciamento de conteúdos que busca viabilizar e favorecer a relação do sujeito com o conhecimento" (FORATO et al., 2011, p. 42) é característica da programabilidade de aquisição do saber, que descreve todos os caminhos que compõem a efetivação e organização do Saber a Ensinar. A programabilidade do saber permite o controle so- 
cial de aprendizagem, que viabiliza sua apropriação pelos sujeitos que formam do Saber a Ensinar (VERRET, 1975, apud CHEVALLARD, 1991).

Portanto, a falta de informação sobre o tempo de aplicação da intervenção didática, diante da importância de descrever os passos que norteiam a aplicação do Saber a Ensinar para exercer o controle social de aprendizagem, é uma limitação identificada em $23 \%$ das propostas didáticas selecionadas nessa pesquisa.

\section{III.6 Nível de ensino}

Quanto ao nível de ensino, das 43 propostas selecionadas, 20 foram elaboradas para cursos de formação de professores, aproximadamente $46 \%$, cerca de $49 \%$ foram desenvolvidas para o Ensino Médio e 5\% para o Ensino Fundamental. Entre as propostas didáticas elaboradas para cursos de formação de professores, se encontram trabalhos voltados para cursos de licenciatura, bacharelado e formação continuada. Entretanto, a proposta didática $\mathbf{1 1}$ foi elaborada para ser utilizada com alunos do ensino médio, mas, segundo a autora, pode ser adaptada para o ensino fundamental e superior. O gráfico abaixo ilustra os níveis para os quais as propostas didáticas selecionadas foram elaboradas.

Gráfico 6: Distribuição por nível de ensino, das propostas didáticas selecionadas (total = 43 propostas).

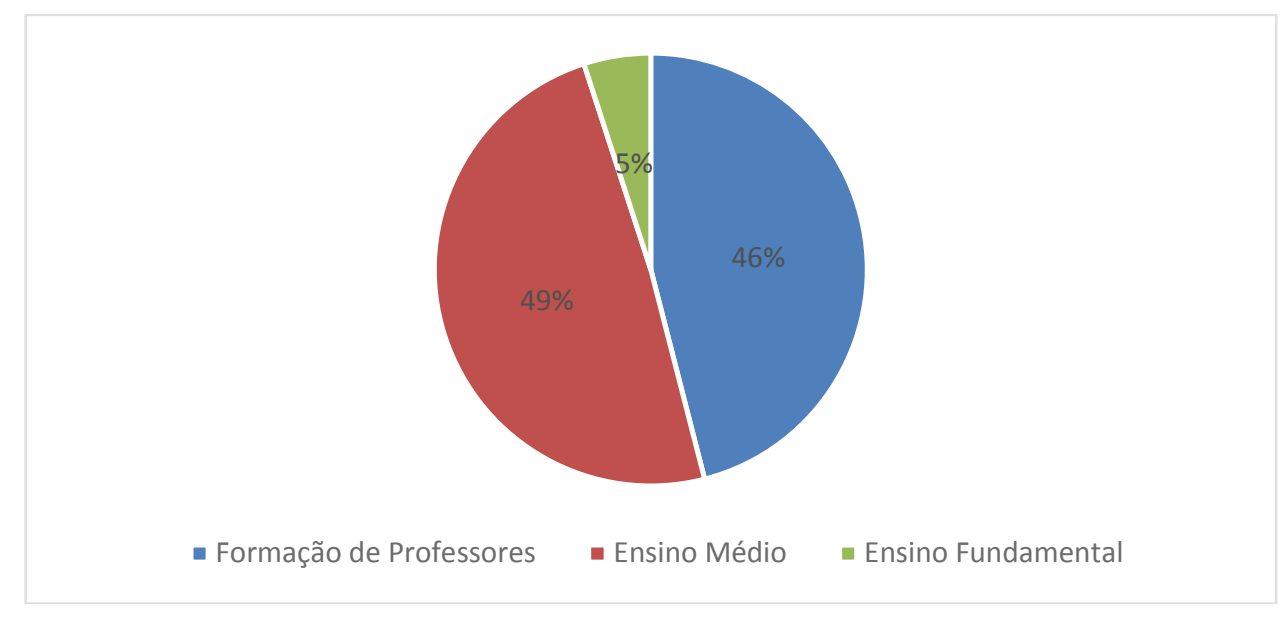

Fonte: elaborado pelo autor da pesquisa.

Entre as propostas didáticas publicadas em periódicos brasileiros especializados da área, a maioria das intervenções (65\%) foi aplicada para estudantes dos cursos de nível superior. No cenário internacional a maioria das pesquisas empíricas analisadas na interface entre a abordagem histórica e o EF é voltada para o nível fundamental e médio (TEIXEIRA et al., 2012a).

Incluir de maneira efetiva a abordagem histórica nos cursos de formação inicial e continuada de professores de física é uma estratégia capaz de contribuir com a utilização efi- 
caz da $\mathrm{HC}$ no EF. O contato com as vantagens e desafios que envolvem a interface gerada entre essas duas áreas, pode influenciar uma mudança de postura dos futuros docentes frente a estratégias de ensino inovadoras. Para Martins (2006), a criação de cursos de pós-graduação específico da área pode gerar um "efeito cascata", ou seja, professores com formação adequada para utilizar esse tipo de abordagem nos cursos de formação de professores e na escola básica.

Outra característica positiva identificada na análise geral das propostas didáticas selecionadas é a utilização da abordagem histórica na formação tanto de licenciados quanto de bacharelados em física. Utilizar a abordagem histórica na formação de licenciados a bacharéis, parte do pressuposto que a discussão de aspectos da $\mathrm{HC}$ pode contribuir para enriquecer a percepção crítica e consciente sobre os procedimentos científicos entre professores e cientistas, além de possibilitar uma compreensão sobre NdC (MARTINS, 1990; MATTHEWS, 1994).

\section{III.7 Estratégias de ensino}

Elaborar atividades de ensino capazes de contribuir para a efetivação dos objetivos pretendidos com a utilização da abordagem histórica é um dos obstáculos definidos por Forato (2009), para a utilização desse tipo de abordagem no EF. A fim de superar esse desafio, foram desenvolvidas, em seu trabalho (Proposta 11), atividades capazes de tornar a aplicação da proposta dinâmica, interessante e desafiadora.

Dentre as estratégias de ensino adotadas para o processo de aplicação das propostas didáticas analisadas, existe uma grande predominância de leitura e discussões de textos, bem como de aulas expositivas. Pelo menos $73 \%$ das propostas definem a leitura, discussão de textos e as aulas expositivas como estratégias para o processo de utilização da HC no EF.

Além das leituras, as propostas didáticas 11 e 22 propõem a realização de atividades teatrais. A proposta 11 justifica a realização de uma peça teatral como uma estratégia capaz envolver os alunos numa atividade envolvente e intrigante. A proposta $\mathbf{1 7}$ propôs a realização de experimentos, utilizando materiais de baixo custo, e os trabalhos $\mathbf{1 2}$ e $\mathbf{9}$ optaram por atividades experimentais demonstrativas. A resolução de problemas, também foi uma estratégia de ensino utilizada, principalmente, entre os trabalhos que abordam assuntos de Mecânica e Ótica. A proposta 15, por sua vez, utilizou a abordagem histórica no EF a partir do desenvolvimento de projetos relacionados a Ondas Eletromagnéticas ao longo de encontros que culminaram numa jornada de iniciação científica.

$\mathrm{O}$ uso de roteiros e/ou questões para nortear o processo de leitura dos textos que compõem a proposta didática é uma estratégia utilizada pelos autores das propostas $\mathbf{1 6}$ e $\mathbf{4 2}$, por exemplo. De acordo com os autores desses trabalhos, essa estratégia contribui para despertar o interesse dos alunos pela leitura, bem como evitar a ocorrência de um distanciamento entre a leitura e os objetivos esperados pelo docente durante a discussão dos textos. 
O processo de análise geral das propostas didáticas de física, orientadas por abordagens históricas, evidencia uma diversidade de estratégias didáticas adotadas para o processo de utilização da HC no EF. A heterogeneidade de estratégias didáticas define outra característica positiva das propostas didáticas, pois a maioria das intervenções $(95 \%)$ descreve as estratégias de ensino envolvidas no processo de efetivação do Saber a Ensinar dentro da perspectiva histórica para o EF.

Ao fim do processo de análise geral é possível concluir, de modo geral, que os trabalhos apresentam uma boa qualidade na maioria dos aspectos descritos como importantes para a compreensão do processo de transposição didática, realizado pelos autores de propostas didáticas de física orientadas por abordagens históricas.

Com a aplicação dos critérios de corte, apenas duas propostas didáticas serão analisadas segundo os critérios de análise.

\section{III.8 Análise pormenorizada das propostas didáticas de física, orientadas por aborda- gens históricas}

Após a análise geral das propostas didáticas de física, orientadas por abordagens históricas, será apresentada a análise pormenorizada das propostas que atendem aos critérios de corte $^{25}$ (Propostas 5 e 21).

Quadro 4: Propostas didáticas que atendem aos critérios de corte.

\begin{tabular}{|c|c|c|c|c|}
\hline Trabalho & $\begin{array}{c}\text { Dissertação } \\
\text { (D)/Tese (T) }\end{array}$ & Ano & Autor & Título \\
\hline $\mathbf{5}$ & $\mathrm{T}$ & 2005 & $\begin{array}{c}\text { GATTI, } \\
\text { S. R. T. }\end{array}$ & $\begin{array}{r}\text { Uma análise de uma ação didática centrada na utilização } \\
\text { da história da ciência: uma contribuição para a formação } \\
\text { inicial do docente de física. }\end{array}$ \\
\hline $\mathbf{2 1}$ & $\mathrm{T}$ & 2011 & $\begin{array}{c}\text { DANIEL, } \\
\text { G. P. }\end{array}$ & $\begin{array}{r}\text { História da ciência em um curso de licenciatura em física: } \\
\text { a gravitação newtoniana e a gravitação einsteiniana como } \\
\text { exemplo. }\end{array}$ \\
\hline
\end{tabular}

Ao analisarmos esses trabalhos, identificamos que ambas selecionaram as concepções sobre $\mathrm{NdC}$ que desejavam enfatizar ao longo da proposta didática. A proposta didática $\mathbf{5}$ possui o objetivo de questionar uma visão simplista, cumulativa e neutra da construção do conhecimento científico e, assim, contribuir para desmistificar esse tipo de visão sobre a Ciência (GATTI, 2005).

Uma concepção cumulativa da ciência, questionada pela proposta $\mathbf{5}$, é uma concepção que apresenta o desenvolvimento científico como resultado de uma evolução linear, simples e sem crises. Bastante comum no ensino de ciências, esse tipo de visão negligencia os

\footnotetext{
25 (a) analisar apenas propostas que almejam discutir concepções sobre natureza da ciência em seus objetivos pedagógicos; (b) analisar apenas as propostas didáticas que utilizam a Gravitação Universal (GU) de Newton como temática histórica.
} 
momentos de crises e retrocessos da ciência, ao mostrar o avanço da ciência descontextualizado de processos de mudanças importantes para o seu desenvolvimento. Enquanto que a concepção neutra nega a influência das relações sociais, sejam elas políticas, religiosas ou econômicas, para o conhecimento cientifico (GIL-PÉREZ et al., 2001) ${ }^{26}$.

A proposta didática 21 pretende, ao realizar a interface entre a $\mathrm{HC}$ e o EF, discutir as controvérsias e contribuições socioculturais para a ciência. De acordo com o próprio autor da proposta, questões internas e externas, como a epistemologia e as questões filosóficas e religiosas, devem contribuir para que futuros professores de física possam melhorar suas concepções sobre a ciência (DANIEL, 2011).

A concepção de consenso sobre $\mathrm{NdC}$, comum na literatura sobre educação em ciências e defendida nos trabalhos analisados (Propostas 5 e 21), é fruto de uma perspectiva que defende a importância de evitar algumas interpretações equivocadas sobre o trabalho cientifico, para, a partir da convergência de ideias epistemológicas de diferentes pensadores, elaborar posições aceitáveis acerca do desenvolvimento da ciência (GIL PÉREZ et al., 2001; MARTINS, 2015).

Selecionar e descrever os aspectos sobre NdC que se deseja abordar ao longo da proposta didática é uma característica positiva sobre os trabalhos analisados. Tendo em vista, que a concepção NdC adotada pelos autores deve estar refletida em todos os aspectos que compõem a proposta didática (objetivos pedagógicos, seleção dos aspectos históricos enfatizados, aprofundamento/detalhamento dos episódios históricos, uso de fontes, entre outros). Essa seleção se configura como um importante, e necessário, passo para a elaboração de uma proposta didática de física, orientada por abordagens históricas, que, entre outras coisas, almeja abordar concepções sobre NdC (FORATO, 2009).

O desenvolvimento de uma compreensão adequada da NdC é um dos objetivos mais desejados no ensino de ciências (LEDERMAN, 2007; FORATO, 2009), porém a ideia de consenso, apesar de suas diferentes terminologias, tem sido duramente criticada. Para Irzik e Nola (2010), a principal limitação da visão de consenso está relacionada a desconsideração das particularidades das diferentes áreas das ciências. Porém, é possível encontrar diferentes abordagens sobre "o que ensinar?", quando se busca compreender o funcionamento da Ciência e como o conhecimento científico é produzido, validado e comunicado (MARTINS, 2015).

Os próprios filósofos da ciência expressam diferentes significados sobre $\mathrm{NdC}$, ou seja, não existem concepções efetivas sobre NdC que não possam ser modificadas à luz de estudos realizados por outros pesquisadores (ALTERS, 1997). Entretanto, a discussão e/ou inves-

\footnotetext{
26 Vale ressaltar que esta é uma visão sobre a ciência denominada de ‘visão de consenso', que assume que há um consenso entre os filósofos da ciência contemporânea sobre determinados aspectos acerca da NdC (Gil-Perez et al., 2001). Contudo, os autores deste trabalho concordam com as críticas de Alters e de Irzik e Nola quanto a esta visão de consenso: ALTERS, B. J. Whose Nature of Science? Journal of Research in Science Teaching, New York, v. 34, n. 1, p. 39- 55, 1997; IRZIK, G.; NOLA, R. A family resemblance Approach to the Nature Sicence for Science Education. Science and Education, 20 (5), 591-607, 2011.
} 
tigação de questões relacionadas a NdC no ensino de ciências, de acordo com Martins (2015, p. 717), deve "partir de uma perspectiva mais aberta, plural e heterogênea.

Nesse contexto, a abordagem de semelhança de família (family resemblance), por exemplo, é posta como uma possibilidade, pois se caracteriza como uma concepção abrangente e sistemática, ao reconhecer a existência de características convergentes e divergentes nas ciências. Para Clough (2007), em meio a crítica sobre o ensino de questões sobre NdC em sala de aula, defende que os princípios envolvendo questões sobre NdC devem ser substituídas por questões, que devem ser investigadas nas salas de aula de ciências, ao invés de ensinadas 27 .

As propostas 5 e 21, utilizam diferentes estratégias metodológicas para discutir a $\mathrm{NdC}$ no EF, a partir de uma perspectiva histórica. A proposta 21, por exemplo, utiliza uma abordagem explícita ao assumir e discutir, no corpo da proposta, a concepção sobre NdC que deseja enfatizar. Com o intuito de utilizar uma abordagem explícita, o autor da proposta didática 21, nos encontros que antecedem à aplicação da proposta, discute o indutivismo, o empirismo lógico e a dependência que a observação tem da teoria. Na proposta $\mathbf{5}$ são definidas as concepções sobre $\mathrm{NdC}$ que se deseja questionar, porém não se propõe a discussão explícita dessas concepções no corpo da proposta didática.

A escolha realizada na proposta didática 5 pode estar relacionada ao objetivo geral da pesquisa de doutoramento, à qual a proposta didática se encontra inserida: "avaliar se uma experiência didática centrada na inserção da História da Ciência, levando-se em conta as concepções, experiências e crenças didáticas de futuros docentes pode contribuir para a aceitação de novas metodologias de ensino" (GATTI, 2005, p 13). No entanto, no corpo da proposta 5 são encontrados textos (Texto 2, 4 e 7) que discutem as concepções espontâneas de estudantes. Característica que demonstra que este trabalho discute no corpo da proposta um dos seus objetivos em utilizar a HC no EF: promover discussões sobre a existência e persistência das concepções alternativas sobre a evolução histórica do tema atração gravitacional

Uma estratégia metodológica explícita assume a concepção sobre NdC que embasa a proposta didática, ou seja, define no corpo da proposta didática a visão sobre NdC que pretende discutir, assim como suas principais características, ou seja, os aspectos sobre NdC selecionados devem ser diretamente abordados através de leituras que tratam dos mesmos (TEIXEIRA, 2003).

De acordo com Lederman (2007), qualquer investida que busque discutir concepções sobre NdC com professores de ciências deve ser realizada a partir de uma estratégia explícita. Lederman (2007) chegou a essa conclusão a partir da revisão crítica de literatura, ao qual concluíram que todos os trabalhos que utilizavam uma abordagem explícita conseguiram alcançar resultados satisfatórios ao discutir alguma concepção sobre $\mathrm{NdC}$, enquanto que apenas metade dos trabalhos que adotaram uma abordagem implícita alcançou os objetivos almejados.

\footnotetext{
27 Para uma melhor compreensão sobre o debate envolvendo questões de NdC no ensino ciências, bem como considerações sobre abordagens voltadas para o currículo escolar, na perspectiva do saber sobre a Ciência, ver Martins (2015).
} 
Ao analisarmos as propostas $\mathbf{5}$ e $\mathbf{2 1}$, podemos concluir que os episódios da história da GU, selecionados por ambas as propostas, são adequados para que as concepções sobre $\mathrm{NdC}$ selecionadas pelos autores das propostas sejam abordadas. Isto contribui para que os objetivos pedagógicos pretendidos com a utilização didática da abordagem histórica no EF sejam alcançados.

Um dos textos que compõe a proposta 5, por exemplo, tem como objetivo principal contribuir para evidenciar como a revolução copernicana não foi um "evento isolado" (GATTI, 2005, p. 246), mas foi influenciado por questões sociais. Neste sentido, a autora descreve um dos motivos que levaram Copérnico a não publicar suas ideias.

Entretanto, o Livro das Revoluções ainda teria que esperar muito para ser publicado. A demora e as recusas de Copérnico não eram devidas ao temor de uma perseguição religiosa. Se durante anos relutou em tornar públicas suas ideias, era porque temia não ser capaz de prová-las e defendê-las (GATTI, 2005, p. 246).

A passagem citada pode contribuir para mostrar como as ideias copernicanas foram influenciadas pelo contexto social, conforme a proposta didática defende.

Nos textos que compõem a proposta didática 21, podemos destacar, por exemplo, um trecho que pode contribuir para discutir as controvérsias e contribuições socioculturais para a ciência, objetivo definido pelo autor da proposta:

(...) Copérnico retoma a questão da relatividade ótica dos movimentos, Oresme argumentara, já no século XIV, que, apenas com base em dados físicos ou da razão, não seria possível concluir se a Terra estaria em repouso ou em movimento. Acreditando no repouso da Terra, Oresme sustentava, no entanto, ser isto uma questão de fé (MEDEIROS, 2002, p. 36, apud DANIEL, 2011).

O trecho acima demonstra uma importante relação do desenvolvimento científico com a fé cristã no período em que Copérnico elaborou suas ideias, num contexto em que filósofos naturais apresentavam diversos motivos pelos quais consideravam o universo finito e a Terra imóvel no centro do universo.

Nos textos elaborados pela autora da proposta didática 5, é possível afirmar que os aspectos históricos abordados foram apresentados com uma linguagem formal, voltada para o público ao qual a proposta didática se destina, característica que facilita a compreensão do conteúdo abordado ao longo do texto (FORATO, 2009). Todavia, isso não significa que o texto realizou descrições simplistas sobre a história da física, por outro lado, exemplificou, assim como foi descrito pela análise dos aspectos históricos enfatizados, características importantes sobre a temática abordada, sem sobrevalorizar posições internas ou externas.

O cuidado com textos inteligíveis é uma característica presente, por exemplo, no texto 5 (O modelo de mundo de Ptolomeu), no qual a autora descreve o complexo sistema ptolomaico, para explicar a variação aparente do brilho dos planetas: 
Se o movimento dos planetas fosse descrito a partir de um sistema excêntrico (figu$r a$ b), para um observador em E, o planeta $P$ não pareceria mover-se com velocidade constante ao longo da trajetória em relação às estrelas fixas (apesar de seu movimento ao longo do círculo ser uniforme). Além disso, neste caso, considerando a Terra representada em E e o Sol (ou demais planetas) representado em $P$, haveria períodos em que o Sol ou o planeta estaria mais próximo da Terra, o que explicaria a variação de brilho observada (GATTI, 2005, p. 236).

Diante do processo de análise realizado na pesquisa, exemplificado no exemplo acima, concluímos que o nível dos aspectos históricos enfatizados pelos textos das propostas didáticas é adequado para um curso de formação de professores, para os quais as duas propostas se destinam. Ao analisarmos os textos elaborados e selecionados para compor as propostas 5 e 21, identificamos, também, uma discussão sobre a história da ciência que demonstra as complexas relações inerentes à ciência, especificamente as concepções selecionadas sobre $\mathrm{NdC}$, sem a realização de simplificações históricas.

Os textos didáticos que compõem a proposta 5 foram elaborados pela própria autora. Essa foi uma das estratégias utilizadas pela maioria dos autores das propostas didáticas analisadas anteriormente. Para a elaboração dos textos que formam a proposta 5, a autora utilizou, com maior ênfase, textos historiográficos escritos por especialistas na temática. Porém, ao analisarmos os textos didáticos da proposta didática 5, identificamos citações diretas e indiretas de fontes primárias. O autor da proposta didática 21, por sua vez, optou por selecionar, de outros autores, a maioria dos textos de seu trabalho. Dentre os textos selecionados, encontramos trabalhos historiográficos e textos didáticos que utilizam uma narrativa histórica.

Um dos desafios que compõem os processos envolvidos no desenvolvimento de propostas didáticas de física, orientadas por abordagens históricas, é a seleção de conteúdos e episódios históricos que devem compor a proposta. A seleção dos aspectos históricos deve estar articulada com os objetivos pedagógicos almejados com a elaboração da proposta, e não pode ser excessivamente simplista a ponto de contribuir para a disseminação de uma pseudohistória (FORATO, 2009).

A utilização de fontes primárias ou secundárias (historiográficas) na pesquisa sobre a $\mathrm{HC}$ depende do tipo de pesquisa que se pretende realizar e do tipo de pergunta que se pretende responder, pois existem trabalhos de historiadores da ciência que não necessitam de consultas a fontes primárias (MARTINS, 2005). Todavia, para utilizar a abordagem histórica no EF, Forato et al. (2011) argumentam sobre o cuidado com a utilização de fontes primárias em sala de aula, diante do risco de serem realizadas interpretações equivocadas sobre os aspectos históricos enfatizados. Diante desta questão, estes autores colocam a análise crítica de fontes primárias como uma estratégia para a utilização desse tipo de fonte no ensino (FORATO, 2009). Inserir comentários e figuras, por exemplo, são algumas estratégias que também podem contribuir para uma melhor compreensão de fontes primárias no ambiente educacional (BOSS, 2014). 
Com relação às fontes, ao analisarmos as propostas $\mathbf{5}$ e 21, concluímos que ambas utilizaram fontes primárias e secundárias ao longo dos textos elaborados e selecionados para os trabalhos. Em ambas as propostas percebe-se a preocupação em interpretar os aspectos históricos enfatizados na fonte primária, o que é benéfico para os interessados em utilizar a abordagem histórica no EF. O cuidado em interpretar trechos de fontes primárias contribui para que sejam realizadas interpretações diacrônicas sobre a história da física, evitando a propagação de uma pseudo-história da ciência (FORATO, 2009).

Este cuidado foi observado em alguns trechos dos textos selecionados para compor a proposta didática 21. No segundo encontro, por exemplo, em que foram apresentados os pressupostos da teoria copernicana, são citados diversos trechos da obra de Copérnico, como, por exemplo, a seguinte citação:

(...) quando, por exemplo, o centro da Terra passa por Capricórnio, o Sol aparecenos passando através de Câncer e quando mencionam a Terra em Aquário, o Sol parece estar em Leão (...) (COPÉRNICO, 1942 apud MEDEIROS, 2002, p. 37, extraído de DANIEL, 2011).

Entretanto, a fim de evitar a realização de uma interpretação anacrônica sobre o respectivo trecho, afirma que:

No sexto pressuposto, Copérnico transfere o movimento anual, até então atribuído ao Sol, para a Terra, tornando assim o movimento daquele apenas como algo aparente. Assim, o movimento da Terra em volta do Sol o faz parecer atravessar o zodíaco, localizando-se sempre na extremidade oposta à Terra (MEDEIROS, 2002, p. 37, apud DANIEL, 2011).

O cuidado na seleção das referências que formam os textos sejam eles elaborados ou selecionados, apesar de não ser garantia, pode contribuir para evitar a propagação de uma pseudo-história (FORATO, 2009). Devem ser utilizadas fontes de pesquisadores especializadas na área. Portanto, para que a HC possa ser cada vez mais utilizada no ensino, essas referências, produto do trabalho de pesquisadores especializados, precisa sair dos muros da pesquisa acadêmica e adentrar o ambiente frequentado pelos professores, sejam eles físicos ou virtuais.

Dentre as fontes historiográficas utilizadas nos textos didáticos desenvolvidos pela autora da proposta 5, destacam-se: Peduzzi (1998) e Cohen (1988), entre aquelas mais citadas. Com relação à proposta 21, foram selecionados textos elaborados por diversos pesquisadores, entre eles estão Peduzzi (1998), e Kuhn (1990).

A análise sobre as duas referências mais citadas nos textos didáticos da proposta $\mathbf{5}$, assim como dos autores dos textos selecionados pelo autor da proposta didática $\mathbf{2 1}$, deixa evidente que os autores das propostas didáticas se preocuparam em selecionar referências confiáveis sobre a temática histórica que forma o trabalho. Esse cuidado, apesar de não ser garantia, dificulta a divulgação de erros sobre a HF (MARTINS, 2001). 
Com a análise das propostas didáticas $\mathbf{5}$ e $\mathbf{2 1}$ também é possível inferir sobre alguns desafios encontrados pelos autores para o uso da abordagem histórica nas aulas de física. A autora da proposta $\mathbf{5}$, por exemplo, destaca a resistência dos licenciandos para a adoção de novas práticas de ensino, neste caso ao uso didático da HC no EF. A falta de interesse do público ao qual a proposta se destina, o conhecimento insuficiente sobre o tema e a falta de tempo foram os principais desafios apontados pelos licenciandos para esse tipo de postura frente ao uso didático da abordagem histórica em sala de aula.

O autor da proposta $\mathbf{2 1}$ descreve que o uso da $\mathrm{HC}$, a partir de uma prática reflexiva e dialógica, gerou uma resistência dos futuros professores de física para o uso didático desse tipo de abordagem no ambiente de ensino. De acordo com os licenciandos, essa proposta exigia uma mudança de postura, ou seja, o abandono de uma postura passiva frente ao processo de ensino e aprendizagem.

As ideias, crenças, atitudes e concepções sobre o processo de ensino e aprendizagem construídos pelos licenciandos, ao longo de sua vida escolar, constitui uma das razões de resistência para o desenvolvimento de ações didático-pedagógicas voltadas para o uso da abordagem histórica no EF (HÖTTECHE; SILVA, 2011). Perante o exposto, os professores que almejam elaborar e posterior aplicar uma proposta didática de física, orientada por abordagens históricas, devem estar cientes dos desafios a serem contornados a partir de negociações e estratégias pedagógicas, diante da impossibilidade de solucionar completamente todos os desafios que envolvem a utilização desse tipo de abordagem nas salas de aula de física. Sendo importante para superar e contornar esses desafios, realizar escolhas e assumir riscos (FORATO, 2009).

\section{Conclusões}

A análise geral sobre o processo de transposição didática adotada pelos autores de propostas didáticas de física, orientadas por abordagens históricas, fornece informações relevantes para a elaboração de intervenções que venham contribuir para aproximar de forma efetiva e com exemplos empíricos a $\mathrm{HC}$ do EF. Entre os aspectos analisados, destacam-se:

(1) O número significativo de trabalhos que utilizam assuntos relacionados a FMC. Aspecto que atende uma perspectiva defendida por pesquisadores da área de ensino de ciências, bem como os PCN, sobre a necessidade de uma formação voltada para uma cultura científica, que permita a interpretação de fatos e fenômenos naturais.

(2) Variedade de objetivos pedagógicos pretendidos como uso da abordagem histórica no EF, o que mostra que esse tipo de abordagem pode ser utilizado para distintos fins didáticos.

(3) A elaboração dos textos que compõem a proposta didática, tendo em vista que encontrar materiais didáticos voltados para a interface entre a $\mathrm{HC}$ e o EF é um obstáculo que precisa ser contornado (FORATO, 2009). Todavia, o estudo também aponta que a seleção de 
texto é uma estratégia possível para a elaboração e aplicação de propostas didáticas de física, orientadas por uma abordagem histórica;

(4) Uso de fontes primárias para diferentes objetivos pedagógicos e níveis de ensino, a partir do uso de estratégias que evitem uma interpretação equivocada desse tipo de fonte.

A análise pormenorizada mostrou o cuidado na seleção das referências que formam os textos que foram elaborados e/ou selecionados para compor as propostas didáticas. Esse é um cuidado que pode contribuir para evitar a propagação de uma concepção errada sobre a HC (FORATO, 2009). Essa seleção deve ser um reflexo das concepções sobre NdC que se deseja abordar ao longo da proposta didática. Os aspectos devem ser previamente definidos a fim de subsidiar as escolhas e riscos que se devem assumir para a realização do processo de transposição didática que envolve o uso da HC no EF.

Utilizar a $\mathrm{HC}$ no ensino de ciências, em especial no EF, não é uma tarefa simples, exige o uso de conhecimentos de diferentes áreas a fim de evitar transmitir concepções erradas sobre a Ciência. O caminho é longo, nele se encontram os mais diversos obstáculos, porém ao analisarmos as propostas didáticas de física, orientadas por abordagens históricas, podemos concluir que entre as adversidades é possível construir um EF mais contextualizado. Tendo em vista que a partir do uso da abordagem histórica, se possa contribuir para: (i) Evidenciar a Ciência como construção humana; (ii) Enriquecer a formação cultural dos estudantes; (iii) Motivar os alunos; (iv) Proporcionar uma melhor compreensão dos conceitos científicos; (v) Destacar a relação entre CTS.

Por fim, esperemos com essa pesquisa, contribuir para aproximar, de forma efetiva e com exemplos empíricos, a HC do EF. Considerando-se que os resultados apresentados neste trabalho, fornecem uma gama de recomendações sobre a utilização empírica da abordagem histórica no EF, capaz de contribuir para a elaboração e, consequentemente, implementação da HC no EF, "para que se possa ter uma melhor compreensão da sua eficácia em situações reais de sala de aula" (TEIXEIRA et al., 2012a, p. 32).

\section{Referências}

ALTERS, B. J. Whose nature of science? Journal of Research in Science Teaching, v. 34, n. 1, p. 39-55, 1997.

AZEVEDO H. L.; MONTEIRO, Jr., F. N.; SANTOS,T. P. dos; TANCREDO. B. N.; CARLOS, J. G.; NARDI, R. O uso do experimento no Ensino da Física: tendências a partir do levantamento dos artigos em periódicos da área no Brasil. In: ENCONTRO NACIONAL DE PESQUISA EM EDUCAÇÃO EM CIÊNCIAS, 7, 2009, Florianópolis. Atas... 2009.

BEZERrA, E. V. Lima. Análise das Propostas Didáticas de História e Filosofia da Ciência para o Ensino de Física. 2014. 223f. Dissertação (Mestrado em Educação em Ciências e em Matemática) - Universidade Federal do Paraná, Curitiba. 
BOSS, S. L. B. Considerações sobre a produção e o uso de material histórico em sala de aula: dificuldades de leitura e entendimento de traduções de fontes primárias. In: CAMARGO, S. (Org.). Controvérsias na Pesquisa em Ensino de Física. 1ed. São Paulo: Livraria da Física, 2014. cap. 8. p. 161-174.

CARVALHO, A. M. P.; VANNUCCHI, A. I. O currículo de física: inovações e tendências nos anos noventa. Revista Investigações em Ensino de Ciências, IF-UFRGS, v. 1, n.1, p. 3$19,1996$.

CHEVALLARD, Y. La transposición didáctica: del saber sabio al saber enseñado. Buenos Aires: Aique, 1991.

COHEN, I. B. O nascimento de uma nova Física. Tradução: Maria Alice Gomes da Costa. Lisboa: Gradiva, 1988. 305p.

CLOUGH, M. P. Teaching the nature of science to secondary and post-secondary students: questions rather than tenets. The Pantaneto Forum, 25, 2007. Disponível em: $<$ http://www.pantaneto.co.uk/issue25/front25.htm>. Acesso em: 12 jul. 2018.

DANIEL, G. P. História da ciência em um curso de licenciatura em Física: a gravitação newtoniana e a gravitação einsteiniana como exemplares. Tese. 404p. Florianópolis: UFSC, 2011.

FORATO, T. C. M. A natureza da ciência como saber escolar: um estudo de caso a partir da história da luz. 2009. Tese (Doutorado) - USP. Disponível em: <http://www.teses.usp.br/ teses/disponiveis/48/48134/tde-24092009-130728/pt-br.php>. Acesso em: 12 jun. 2017.

FORATO, T. C. M.; MARTINS, R. A.; PIETROCOLA, M. Historiografia e Natureza da Ciência na sala de aula. Caderno Brasileiro de Ensino de Física, Florianópolis, v. 28, n. 1, p. 27-59, abr. 2011. Disponível em: <https://periodicos.ufsc.br/index.php/fisica/article/view/ 2175-7941.2011v28n1p27>. Acesso em: 23 jun. 2017.

GATTI, S. R. T.; NARDI, R. História da Ciência no Ensino de Física: algumas relações entre as concepções e as práticas de futuros docentes. In: NARDI, R. BASTOS, F. (Org.). Formação de Professores e Práticas Pedagógicas no Ensino de Ciências: contribuições de pesquisas na área. São Paulo: Escrituras, 2008.

GIL-PÉREZ, D.; MONTORO, I. F.; ALÍS, J. C.; CACHAPUZ, A.; PRAIA, J. Para uma imagem não deformada do trabalho científico. Ciência \& Educação, v. 7, n. 2, p. 125-153, 2001.

GRECA, I. M. R.; ARRIASSECQ, I. ; TEIXEIRA, E. S. El Uso de la Historia y la Filosofía de la Ciencia en las Clases de Física. In: VILLAGRÁ, J. A. M.; GEBARA, M. J. F. (Org.). Estrategias Didácticas para la Enseñanza de la Física. 1 ed. Burgos: Servicio de Publicaciones e Imagen Institucional, UNIVERSIDAD DE BURGOS, 2018. cap. 2. p. 43-61. 
CLOUGH, M. P. Teaching the nature of science to secondary and post-secondary students: questions rather than tenets. The Pantaneto Forum, 25, 2007. Disponível em: <file://C:/Users/1837352/Downloads/QuestionsRatherThanNOSTenets.pdf>. Acesso em: 12 jul. 2018.

HÖTTECKE, D.; SILVA, C. C. Why implementing History and Philosophy in School Science Education is a challenge: an analysis of obstacles. Science \& Education, Dordrecht, n. 20, p. 293-316, 2010. Disponível em: <https://link.springer.com/article/10.1007/s11191-0109285-4>. Acesso em: 11 fev. 2018.

IRZIK, G.; NOLA, R. A family resemblance approach to the Nature of Science for Science Education. Science \& Education, v. 20, n. 7-8, p. 591-607, 2011.

KUHN, T. S. A revolução copernicana: a astronomia planetária no desenvolvimento do pensamento ocidental. Lisboa: Ed. 70, 1990.

LEDERMAN, N. G. Nature of science: past, present and future. In: ABELL, S. K.; LEDERMAN, N. G. (Eds.). Handbook of Research on Science Education. Mahwah, New Jersey: Lawrence Erlbaum Publishers, 2007. cap. 28. p. 831-880.

MARTINS, A. F. P. Natureza da Ciência no ensino de ciências: uma proposta baseada em temas e questões. Caderno Brasileiro de Ensino de Física, v. 32, n. 3, p. 703-737, dez. 2015.

MARTINS, R. A. Como não escrever sobre a história da física - um manifesto historiográfico. Revista Brasileira de Ensino de Física, v. 23, n. 1, mar. 2001.

MARTINS, R. A. A História das Ciências e seus usos na educação. In: SILVA, C. C. (Org). Estudos de História e Filosofia das Ciências: subsídios para aplicação no ensino. São Paulo: Livraria da Física, 2006. Introdução.

MATTHEWS, M. R. História, filosofia e ensino de ciências: a tendência atual de reaproximação. Caderno Catarinense de Ensino de Física, Florianópolis, v. 12, n. 3, p. 164-214, dez. 1995.

MEDEIROS, A. Entrevista com Tycho Brahe. Física na Escola, v. 2. n. 2, p. 20-30, 2001.

Entrevista com Kepler: do seu nascimento à descoberta das duas primeiras leis. Física na Escola, v. 3. n. 2, p. 20-33, 2002.

NETO, J. S.; CAVALCANTI, C. J. H.; OSTERMANN, F. Estratégias discursivas adotadas por professores em formação na compreensão do fenômeno da complementaridade em atividades didáticas mediadas pelo interferômetro virtual de Mach-Zehnder. Revista Brasileira de Pesquisa em Educação em Ciências, São Paulo, v. 15, n. 2, p. 293-320, mai/ago. 2015. 
PAGLIARINI, C. R. Uma análise da história e filosofia da ciência presente em livros didáticos de física para o ensino médio. 2007. 115f. Dissertação (mestrado em Ciências) Instituto de Física, USP, São Carlos.

PEDUZZI, L. O. Q. As concepções espontâneas, a resolução de problemas e a história e a filosofia da ciência em um curso de mecânica. Tese (Doutorado em Ensino de Ciências Naturais) - Programa de Pós-Graduação em Educação, Universidade Federal de Santa Catarina, Santa Catarina, 1998.

PEDUZZI; L. O. Q. Sobre a utilização didática da História da Ciência. In: PIETROCOLA, M. (Org.) Ensino de Física: conteúdo, metodologia e epistemologia numa concepção integradora. Florianópolis: Editora da UFSC, 2001. cap. 7, p.1.

SCHIRMER, S. B.; SAUERWEIN, I. P. S. História e filosofia da ciência para sala de aula no EPEF (2002-2010). In: ENCONTRO DE PESQUISA EM ENSINO FÍSICA, XIII, 2011, Foz do Iguaçu, PR.

SILVEIRA, F. L.; PEDUZZI, L. O. Q. A premissa metafísica da revolução copernicana. Caderno Brasileiro de Ensino de Física, Florianópolis, v. 19, n. 3, p. 407-410, dez. 2002.

Três episódios de descoberta científica: da caricatura empirista a uma outra história. Caderno Brasileiro de Ensino de Física, Florianópolis, v. 23, n. 1, p. 26-52, abr. 2006.

TEIXEIRA, E. S.; GRECA, I.; FREIRE, O. The History and Philosophy of Science in Physics Teaching: a research synthesis of didactic interventions. Science and Education, v. 21, n. 6, p. 771-796, 2012a.

TEIXEIRA, E. S.; GRECA, I. M.; FREIRE, O. Uma revisão sistemática das pesquisas publicadas no Brasil sobre o uso didático de História e Filosofia da Ciência no Ensino de Física. In: PEDUZZI, L. O. Q.; MARTINS, A. F. P.; HIDAlGO, J. M. (Orgs.) Temas de História e Filosofia da Ciência no Ensino. Natal, Editora da UFRN, 2012b, cap. 1, p. 9-40.

VANNUCCHI, A. I. História e Filosofia da Ciência: da teoria para a sala de aula. 1996, 131f. Dissertação (Mestrado em Ensino de Ciências) - USP, São Paulo.

\section{Anexo A- Lista das propostas didáticas selecionadas}

1. VANNUCCHI, A. I. História e Filosofia da Ciência: da teoria para a sala de aula. 1996, 131f. Dissertação (Mestrado em Ensino de Ciências) - USP, São Paulo.

2. PEDUZZI, L. O. Q. As concepções espontâneas, a resolução de problemas e a história e a filosofia da ciência em um curso de mecânica. 1998. Tese (Doutorado em Ensino de Ciências Naturais) - Programa de Pós-Graduação em Educação, Universidade Federal de Santa Catarina, Santa Catarina. 
3. TEODORO, S. R. A história da ciência e as concepções alternativas de estudantes como subsídios para o planejamento de um curso sobre atração gravitacional. 2000, 327f. Dissertação (Mestrado em Educação para a Ciência) - Faculdade de Ciências, Universidade Estadual Paulista, Bauru.

4. BASSO, A. C. O átomo de Bohr no nível médio: uma análise sob o referencial lakatosiano. 2004. 198f. Dissertação (Mestrado em Educação Científica e Tecnológica) - Centro de Ciências Físicas e Matemáticas Programa de Pós-Graduação em Educação Científica e Tecnológica, Universidade Federal de Santa Catarina, Santa Catarina.

5. GATTI, S. R. T. Uma análise de uma ação didática centrada na utilização da história da ciência: uma contribuição para a formação inicial do docente de física. 2005, 329f. Tese (Doutorado em Educação) - Faculdade de Educação, Universidade Estadual de Campinas, Campinas.

6. MELO, A. C. S. Contribuições da epistemologia histórica de Bachelard no estudo da evolução dos conceitos da óptica. 2005. 198f. Dissertação (Mestrado em Educação Científica e Tecnológica) - Centro de Ciências Físicas e Matemáticas Programa de Pós-Graduação em Educação Científica e Tecnológica, Universidade Federal de Santa Catarina, Santa Catarina.

7. PORTELA, S. I. C. O uso de casos históricos no ensino de física: um exemplo em torno da temática do horror da natureza ao vácuo. 2006. 96f. Dissertação (Mestrado em Ensino de Ciências) - Programa de Pós-Graduação em Ensino de Ciências, Universidade de Brasília, Brasília.

8. DUARTE, R. C. B. Módulo de ensino de mecânica newtoniana com uso de abordagem CTS-histórica. 2006. 231f. Dissertação. Programa de Pós-Graduação em Ensino de Ciências. Mestrado Profissionalizante em Ensino de Ciências. Universidade de Brasília, Distrito Federal.

9. SILVA, O. H. M. Um estudo sobre a estruturação e aplicação de uma estratégia de ensino de física inspirada em lakatos com a reconstrução racional didática para auxiliar a preparar os estudantes para debates racionais entre teorias e /ou concepções rivais. 2008. 208f. Tese (Doutorado em Educação para a Ciência) - Faculdade de Ciências, Universidade Estadual Paulista, Bauru.

10. SOUZA, J. A. Uma abordagem histórica para o ensino do princípio de inércia. 2008. 176f. Dissertação. Programa de Pós-Graduação em Ensino de Ciências Naturais e Matemática. Universidade Federal do Rio Grande do Norte, Natal.

11. FORATO, T. C. M. A Natureza da Ciência como Saber Escolar: um estudo de caso a partir da história da luz. 2009. 220f. Tese (Doutorado em Educação) - Faculdade de Educação, FEUSP, São Paulo. 
12. IACHEL, G. Um estudo exploratório sobre o ensino de astronomia na formação continuada de professores. 2009. 230f. Dissertação (Mestrado em Educação para a Ciência) Faculdade de Ciências, Universidade Estadual Paulista, Bauru.

13. SILVA, W. L. R. A importância de uma abordagem epistemológica na graduação em Física. 2009. 147f. Dissertação (Mestrado em Ensino de Ciências e da Matemática) - Programa de Pós-Graduação em Ensino de Ciências e Matemática (PPECM), Centro Federal de Educação Tecnológica, Rio de Janeiro.

14. SILVA, D. A. Aspectos epistemológicos da Física newtoniana na formação científica. 2009. 196f. Dissertação (Mestrado em História e Filosofia da Ciência) - Centro de Ciências Físicas e Matemáticas Programa de Pós-Graduação em Educação Científica e Tecnológica, Universidade Federal de Santa Catarina, Florianópolis.

15. DUQUE, E. R. História da ciência e o uso da instrumentalização: construção de aparato histórico-científico simples como estratégia de ensino. 2009. 90f. Dissertação (Mestrado em Ensino de Ciências e da Matemática) - Programa de Pós-Graduação em Ensino de Ciências e Matemática (PPECM), Centro Federal de Educação Tecnológica, Rio de Janeiro.

16. SILVA, B. V. C. Controvérsias sobre a natureza da luz: uma aplicação didática. 2010. 183f. Dissertação - Programa de Pós-Graduação em Ensino de Ciências Naturais e Matemática, Universidade Federal do Rio Grande do Norte, Natal.

17. PEREIRA, R. A. A física da música no renascimento: uma abordagem históricoepistemológica. 2010. 107f. Dissertação (Mestrado em Ensino de Ciências) - Instituto de Física e Faculdade de Educação, Universidade de São Paulo, São Paulo.

18. ARTHURY, L. H. M. A cosmologia moderna a luz dos elementos da epistemologia de Lakatos. 2009. 133f. Dissertação (Mestrado em Educação Científica e Tecnológica) - Centro de Ciências Físicas e Matemáticas Programa de Pós-Graduação em Educação Científica e Tecnológica, Universidade Federal de Santa Catarina, Santa Catarina.

19. MELO, A. C. S. Transposição didática do modelo de Huygens: uma proposta para a física escolar. 2010. 192f. Tese (Doutorado em Educação Científica e Tecnológica) - Programa de Pós-Graduação em Educação Científica e Tecnológica, Universidade Federal de Santa Catarina, Florianópolis.

20. MORAIS, A. V. O conceito de energia através da história: a história e a filosofia da ciência como caminho para inserir física moderna e contemporânea na primeira série do ensino médio. 2011. 191f. Dissertação (Mestrado em Ensino de Ciências e da Matemática) Programa de Pós-Graduação em Ensino de Ciências e Matemática (PPECM), Centro Federal de Educação Tecnológica, Rio de Janeiro. 
21. DANIEL, G. P. História da ciência em um curso de licenciatura em física: a gravitação newtoniana e a gravitação einsteiniana como exemplo. 2011. 404f. Tese (Doutorado em Educação Científica e Tecnológica) - Programa de Pós-Graduação em Educação Científica e Tecnológica, Universidade Federal de Santa Catarina, Santa Catarina.

22. HENRIQUE, A. B. Discutindo a natureza da ciência a partir de episódios da história da Cosmologia. 2011. 261f. Dissertação (Mestrado em Ensino de Ciências) - Instituto de Física, Instituto de Química, Instituto de Biociências e à Faculdade de Educação, Universidade de São Paulo, São Paulo.

23. CORDEIRO, M. D. Dos Curie a Rutherford: aspectos históricos e epistemológicos da radioatividade na formação científica. 2011. 234f. Dissertação (Mestrado em Educação Científica e Tecnológica) - Programa de Pós-Graduação em Educação Científica e Tecnológica, Universidade Federal de Santa Catarina, Santa Catarina.

24. FILHO, M. A. Demanda epistemológica no ensino de Física. 2011. Dissertação (Mestrado em Ensino de Ciências e da Matemática) - Programa de Pós-Graduação em Ensino de Ciências e Matemática (PPECM), Centro Federal de Educação Tecnológica, Rio de Janeiro.

25. SCHIRMER, S. B. Textos originais de cientistas e textos sobre história das ideias da ciência na formação inicial de professores de Física. 2012. 155f. Dissertação (Mestrado em Educação em Ciências) - Programa de Pós-Graduação em Ciências: Química da Vida e Saúde, Universidade Federal de Santa Maria, Santa Maria.

26. MOURA, B. A. Formação crítica-transformadora de professores de Física: uma proposta a partir da história da ciência. 2012. 310f. Tese Universidade de São Paulo, São Paulo.

27. JARDIM, W. T. A abordagem histórico-filosófica como caminho para se introduzir o estudo de cosmologia no ensino. 2012, 223f. Dissertação (Mestrado em Ensino de Ciências e da Matemática) - Programa de Pós-Graduação em Ensino de Ciências e Matemática (PPECM), Centro Federal de Educação Tecnológica, Rio de Janeiro.

28. FERNANDES, H. S. Narrativas históricas: discutindo a Natureza da Ciência através de uma abordagem histórico-filosófica. 2012. 133f. Dissertação (Mestrado em Ensino de Ciências e da Matemática) - Programa de Pós-Graduação em Ensino de Ciências e Matemática, Centro Federal de Educação Tecnológica, Rio de Janeiro.

29. ARAÚJO, B. C. História da ciência como estratégia didática no ensino médio: um breve olhar de conteúdos da óptica. 2013. 162f. Dissertação - Programa de Pós-Graduação em Ensino de Ciências Naturais e Matemática, Universidade Federal do Rio Grande do Norte, Natal.

30. OLIVEIRA, W. C. Ensinado sobre a Natureza da Ciência: uma abordagem explícita e contextualizada a partir da história do vácuo. 2013. 473f. Dissertação - Programa de Pós- 
Graduação em Ensino de Ciências Naturais e Matemática, Universidade Federal do Rio Grande do Norte, Natal.

31. RESQUETTI, S. O. Uma sequência didática para o ensino da radioatividade no nível médio, com enfoque na história e filosofia da ciência e no movimento CTS. 2013. 281f. Tese - Programa de Pós-Graduação em Educação para a Ciência e a Matemática do Centro de Ciências Exatas da Universidade Estadual de Maringá, Maringá.

32. SOUZA, R. S. Desafios da história da física na sala de aula: sequência didática, caderno de campo e uma leitura das concepções docente e discente. 2014. 164f. Dissertação - Programa de Pós-Graduação em Ensino de Ciências e Matemática do Centro de Ciências e Tecnologia da Universidade Estadual da Paraíba, Campina Grande.

33. MONTEIRO, M. M. Inércia e Natureza da Ciência no ensino de física: uma sequência didática centrada no desenvolvimento histórico do conceito de inércia. 2014. 232f. Dissertação - Programa de Pós-Graduação em Ensino de Ciências Naturais e Matemática, Universidade Federal do Rio Grande do Norte, Natal.

34. VIEIRA, P. C. Perspectivas sobre a evolução histórica do conceito de luz e sua integração com a fotografia para o ensino de óptica. 2014. 228f. Dissertação - Programa de Pós-Graduação em Ensino de Física, Universidade Federal do Rio Grande do Sul, Porto Alegre.

35. MELLO, A. D. A história e a filosofia da ciência como um caminho para problematizar o tema energia nuclear no ensino médio: as imagens como uma estratégia didática. 2014. 164f. Dissertação (Mestrado em Ensino de Ciências e da Matemática) - Programa de Pós-Graduação em Ensino de Ciências e Matemática, Centro Federal de Educação Tecnológica, Rio de Janeiro.

36. REIS, U. V. Os conceitos de espaço e tempo no ensino de física: uma possibilidade de atuação em sala de aula. 2015. 221f. Dissertação (Mestrado em Ensino de Ciências e da Matemática) - Programa de Pós-Graduação em Ensino de Ciências e Matemática, Centro Federal de Educação Tecnológica, Rio de Janeiro.

37. NETTO, M. F. S. O efeito fotoelétrico e a natureza da luz através de um enfoque histórico-filosófico: uma proposta. 2015. 146f. Dissertação (Mestrado em Ensino de Ciências e da Matemática) - Programa de Pós-Graduação em Ensino de Ciências e Matemática, Centro Federal de Educação Tecnológica, Rio de Janeiro.

38. SIMON, R. A. Do geocentrismo à gravitação universal: proposta e implementação de uma sequência didática para o ensino médio. 2016. 176f. Dissertação - Programa de PósGraduação do Curso de Mestrado Profissional de Ensino de Física, São Carlos. 
39. MATOS, J. A. Apresentando conceitos do movimento de queda dos corpos no ensino fundamental através de um aporte histórico e epistemológico. 2016. 194f. Dissertação Programa de Pós-Graduação em Ensino de Física da Universidade Federal do Rio Grande do Sul, Porto Alegre.

40. FUCHS, E. I. Teoria da relatividade restrita: uma introdução históricoepistemológica e conceitual voltada ao ensino médio. 2016. 337f. Dissertação - Programa de Pós-Graduação em Ensino de Física da Universidade Federal do Rio Grande do Sul, Porto Alegre.

41. NASCIMENTO, B. A. Sequência didática para ensino e aprendizagem do conceito de força numa abordagem histórica. 2016. 94f. Dissertação - Programa de Pós-Graduação Profissional em Ensino de Física da Universidade Federal de Sergipe, São Cristóvão.

42. SANTOS, J. M. O ensino da Gravitação Universal de Newton através da história da ciência e da argumentação: desenvolvimento e análise de uma sequência didática. 2017. 239f. Dissertação - Pós-graduação em Ensino, Filosofia e História das Ciências da Universidade Federal da Bahia e Universidade Estadual de Feira de Santana, Salvador.

43. FONSECA, D. S. Ensinando ciência e sobre ciência com a utilização de fontes primárias da história do vácuo e da pressão atmosférica. 2017. 294f. Dissertação - Programa de Pós-Graduação em Ensino de Ciências Naturais e Matemática, Universidade Federal do Rio Grande do Norte, Natal. 